Supporting Information for

\title{
Metal-Organic Frameworks Stabilize Solution-Inaccessible Cobalt Catalysts for Highly Efficient Broad-Scope Organic Transformations
}

\author{
Teng Zhang, ${ }^{\dagger}$ Kuntal Manna, ${ }^{\dagger}$ and Wenbin Lin* \\ Department of Chemistry, the University of Chicago \\ 929 E 57th Street, Chicago, IL 60637, USA \\ E-mail: wenbinlin@uchicago.edu
}

\section{Table of Contents}

1. General Experimental $\quad$ S2

2. Synthesis and Characterization of Ligands, MOFs, and Metalated MOFs $\quad$ S2-S10

3. Crystallographic Information and Structural Figures S10-S12

4. Spectroscopic Characterization of MOF-Co Species $\quad$ S12-S17

5. X-Ray Absorption Spectroscopic Analysis S17-S25

$\begin{array}{ll}\text { 6. DFT calculation } & \text { S25-S28 }\end{array}$

7. Procedures for Catalytic Hydrogenation of Olefins $\quad$ S28-S35

8. Procedures for Catalytic Hydroboration of Alkenes S36

9. Procedures for Catalytic C-H Borylation of Arenes S36-S37

10. Procedures for Catalytic Hydroboration of Carbonyl Compounds S37-S38

$\begin{array}{ll}\text { 11. References } & \text { S38-S39 }\end{array}$ 


\section{General Experimental}

All of the solvents were purchased from Fisher and used without further purification unless otherwise noticed. All of the other substrates and reagents are commercially available and used as received unless otherwise indicated. 1-octene, styrene, $\alpha$ methylstyrene, cis- $\beta$-methylstyrene, trans- $\beta$-methylstyrene, allyl acetate, and benzaldehyde were distilled and then dried over freshly activated $4 \AA$ molecular sieves prior to use. Cyclohexene, acetophenone, 2-acetylthiophene, 1-decene, 5-methyl-1hexene, 3-methyl-2-butene, and 6-chloro-1-hexene were degassed and then dried with freshly activated $4 \AA$ molecular sieves in a glovebox prior to use. Pinacolborane was purchased from Fisher and was freshly distilled prior to use. ${ }^{1} \mathrm{H}$ NMR spectra were recorded on a Bruker $400 \mathrm{MHz}$ DRX NMR spectrometer and referenced to the proton resonance resulting from incomplete deuteration of the deuterated chloroform $(\delta 7.26)$ or deuterated DMSO $(\delta$ 2.50). ESI-MS spectra were recorded on an Agilent 6130 LC-MS spectrometer with a quadrupole detector. Thermogravimetric analysis (TGA) was performed in air using a Shimadzu TGA-50 equipped with a platinum pan. Powder X-ray diffraction (PXRD) patterns were collected on a Bruker D8 Venture, dual microsource ( $\mathrm{Cu}$ and $\mathrm{Mo}$ ) diffractometer with a $\mathrm{CMOS}$ detector. $\mathrm{Cu} \mathrm{K} \alpha$ radiation was used. The PXRD patterns were processed with the APEX 2 package using PILOT plug-in. Background diffraction signal from glass capillary tube and solvent at $2 \theta \sim 20^{\circ}$ was simulated and removed by the program PowderX. ICP-MS data were obtained with an Agilent 7700x ICP-MS and analyzed using ICP-MS MassHunter version B01.03. Samples were diluted in a $2 \% \mathrm{HNO}_{3}$ matrix and analyzed with a ${ }^{159} \mathrm{~Tb}$ internal standard against a six-point standard curve over the range from $0.1 \mathrm{ppb}$ to $1000 \mathrm{ppb}$. The correlation coefficient was >0.9997 for all analytes of interest. Data collection was performed in Spectrum Mode with five replicates per sample and 100 sweeps per replicate.

\section{Synthesis and Characterization of Ligands, MOFs, and Metalated MOFs}

The bpyv and mPT ligands, bpy-MOF, bpyv-MOF, and mPT-MOF were synthesized as previously reported. ${ }^{1,2}$ 


\subsection{4,4'-(2,2'-Bipyridyl-5,5'-diyl)dibenzoic acid (H2BPP). 5,5'-bis(4-}

methoxycarbonylphenyl)-2,2'-bipyridine ${ }^{3}(320 \mathrm{mg}, 0.75 \mathrm{mmol})$ was dissolved in a mixture of equal volume of $6 \mathrm{M} \mathrm{NaOH}(\mathrm{aq})$ and ethanol and refluxed overnight. After cooling to r.t., the solution was acidified with $2 \mathrm{M} \mathrm{HCl}$ and centrifuged. The solid was washed sequentially with water, ethanol, and ether, then dried under vacuum to afford 4,4'-(2,2'-bipyridyl-5,5'-diyl)dibenzoic acid as a pale yellow solid (260 mg, 87\%). ${ }^{1} \mathrm{H}$ NMR (500 MHz, DMSO- $d_{6}$ ): $\delta 13.12$ (br s, $2 \mathrm{H}$ ), 9.14 (s, $\left.2 \mathrm{H}\right), 8.57$ (d, $2 \mathrm{H},{ }^{3} J_{\mathrm{HH}}=8.0$ $\mathrm{Hz}), 8.38\left(\mathrm{~d}, 2 \mathrm{H},{ }^{3} J_{\mathrm{HH}}=8.5 \mathrm{~Hz}\right), 8.09\left(\mathrm{~d}, 4 \mathrm{H},{ }^{3} J_{\mathrm{HH}}=8.0 \mathrm{~Hz}\right), 7.98\left(\mathrm{~d}, 4 \mathrm{H},{ }^{3} J_{\mathrm{HH}}=8.0\right.$ Hz). ESI-MS: 397.1; calcd. for $[\mathrm{M}+\mathrm{H}]^{+}: 397.1$.

2.2. mBPP-MOF. $\mathrm{ZrCl}_{4}(10 \mathrm{mg}), \mathrm{H}_{2} \mathbf{B P P}(6 \mathrm{mg})$ and 4,4'-bis(carboxyphenyl)-2-nitro1,1'-biphenyl (14 mg) were dissolved in $10 \mathrm{~mL}$ of DMF and $0.1 \mathrm{~mL}$ of trifluoroacetic acid was added. The solution was then heated at $100{ }^{\circ} \mathrm{C}$ for 5 days to afford a pale yellow solid as the MOF product (yield: $17 \mathrm{mg}, 45 \%$ ).

Analysis of digested mBPP-MOF by ${ }^{1} \mathbf{H}$ NMR. To determine the ratio of the two bridging linkers, $10 \mathrm{mg}$ of mBPP-MOF was first washed with THF and dried under vacuum. The resulting solid was then digested in a $1: 1$ mixture of saturated $\mathrm{K}_{3} \mathrm{PO}_{4} / \mathrm{D}_{2} \mathrm{O}$ solution and DMSO- $d_{6}$ and shaken for 5 minutes. The organic layer was then analyzed by ${ }^{1} \mathrm{H}$ NMR and the ratio of BPP ligand and 4,4'-bis(carboxyphenyl)-2-nitro-1,1'-biphenyl ligand was approximately 1:2 as determined by comparing the peaks corresponding to each ligand, which is consistent with the ratio in the feed (Figure S1).

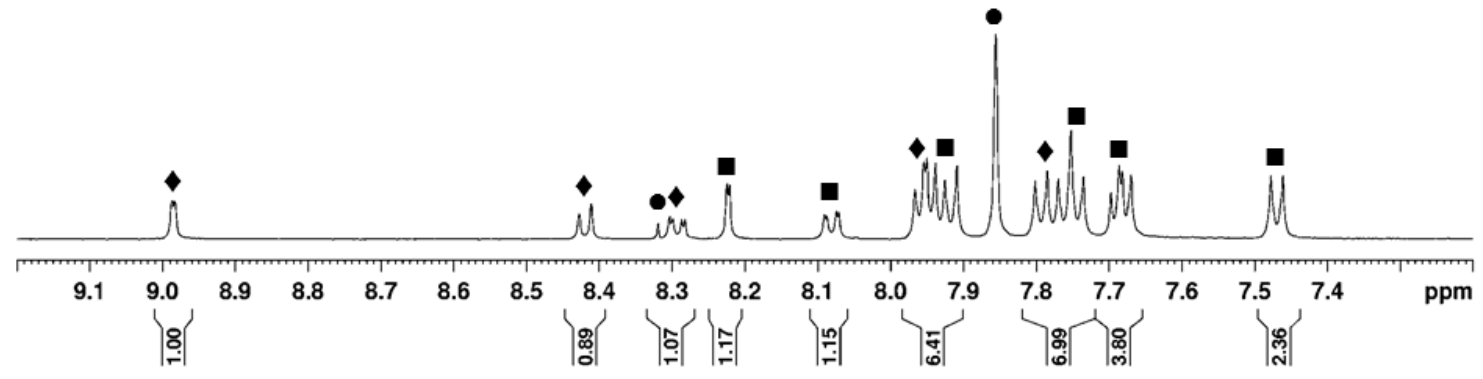

Figure S1. ${ }^{1} \mathrm{H}$ NMR spectrum of mBPP-MOF digested in $\mathrm{K}_{3} \mathrm{PO}_{4} / \mathrm{D}_{2} \mathrm{O} / \mathrm{DMSO}-d_{6}$. Peaks are assigned to the BPP ligand ( $\diamond), 4,4$ '-bis(carboxyphenyl)-2-nitro-1,1'-biphenyl ligand $(\square)$, and residue solvents $(\bullet)$. 


\section{3. bpy-MOF-CoCl .}

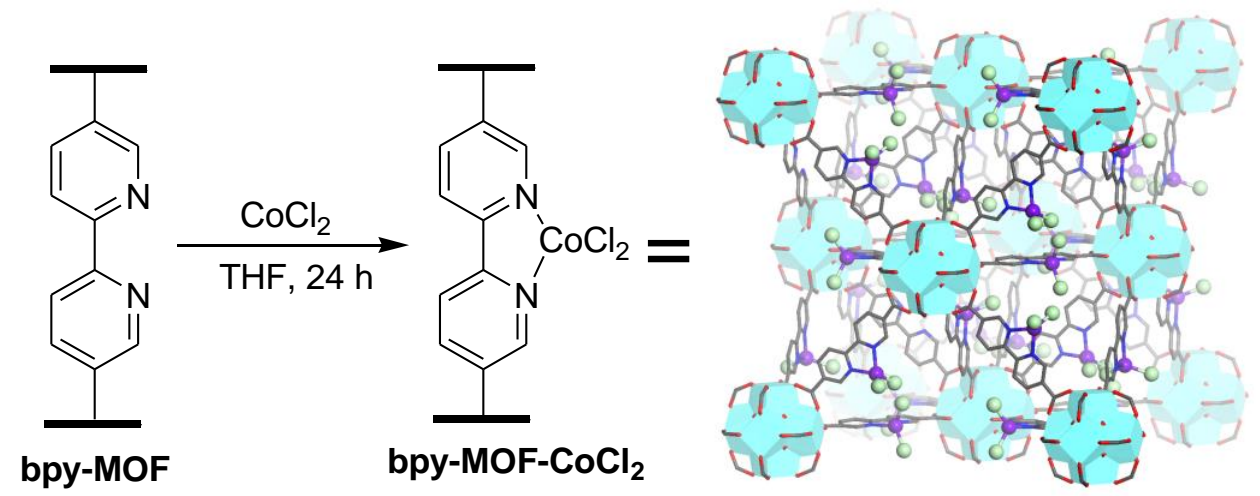

Figure S2. Schematic showing the synthesis and structure of bpy-MOF-CoCl 2 .

In a glovebox, $\mathrm{CoCl}_{2}(13.0 \mathrm{mg}, 0.10 \mathrm{mmol})$ was dissolved in $10 \mathrm{~mL}$ of THF. bpy-MOF (10.0 mg) was weighted onto a filter paper, washed with THF several times, and added to the $\mathrm{CoCl}_{2}$ solution. The resulting suspension was stirred at room temperature slowly overnight and the blue-green solid was then centrifuged out and washed with THF for 4-5 times. The metalated MOFs were then stored in THF in the glovebox for further uses.

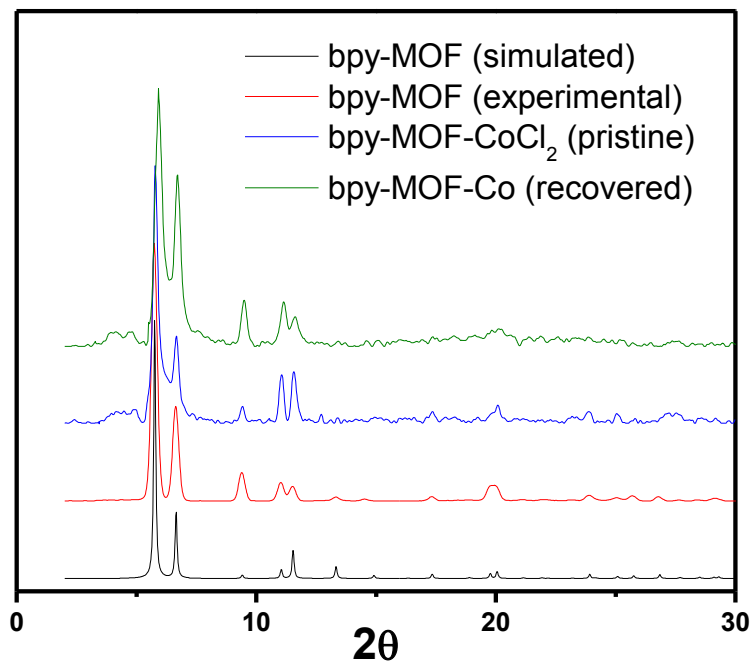

Figure S3. PXRD patterns of bpy-MOF (red), bpy-MOF-CoCl 2 (purple) and bpy-MOFCo (green) recovered after hydrogenation of 1-octene comparing against the simulated pattern for bpy-MOF (black). ${ }^{4}$ 

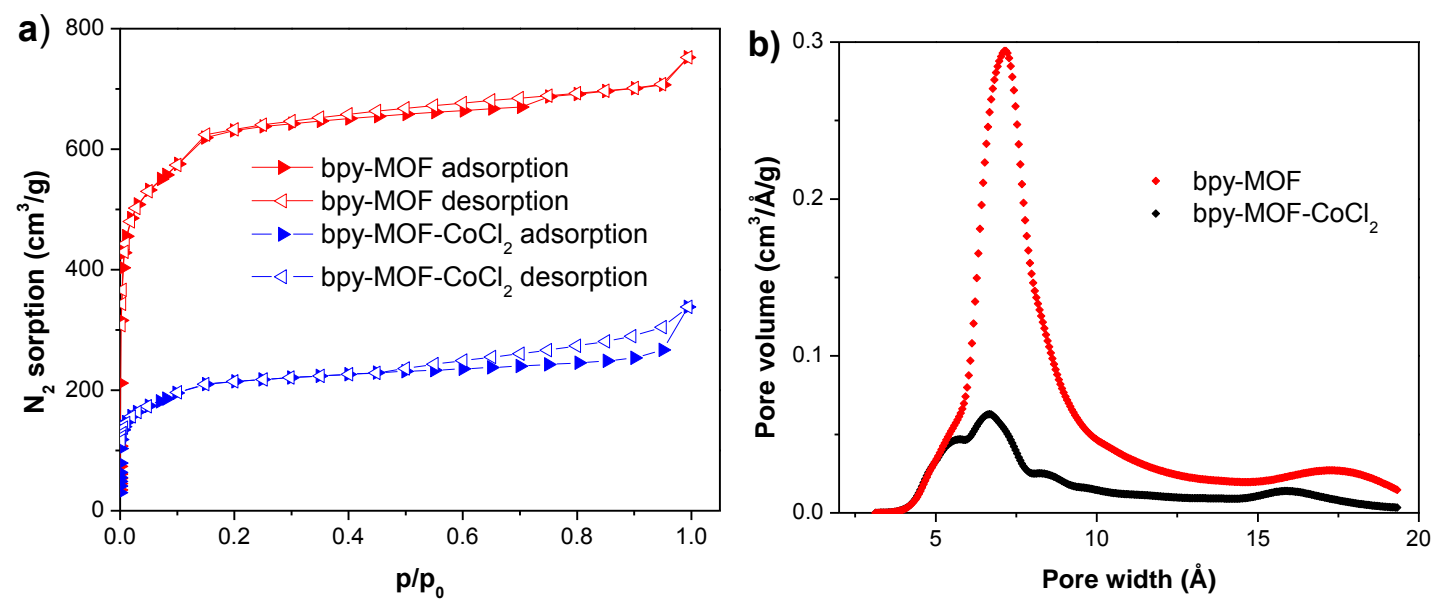

Figure S4. a) Nitrogen sorption isotherms for bpy-MOF and bpy-MOF- $\mathrm{CoCl}_{2}$ at $77 \mathrm{~K}$. BET surface areas for bpy-MOF and bpy-MOF-CoCl $\mathrm{Cl}_{2}$ are 2277 and $764 \mathrm{~m}^{2} / \mathrm{g}$, respectively. ${ }^{2,4}$ b) $\mathrm{HK}$ pore size distribution of bpy-MOF and bpy-MOF- $\mathrm{CoCl}_{2}$.

2.4. bpyv-MOF-CoCl2. In a glovebox, $\mathrm{CoCl}_{2}(13.0 \mathrm{mg}, 0.10 \mathrm{mmol})$ was dissolved in 10 $\mathrm{mL}$ of THF. bpyv-MOF (18.0 mg) was weighted onto filter paper, washed with THF for several times and added to the $\mathrm{CoCl}_{2}$ solution. The resulting suspension was stirred at room temperature slowly overnight and then blue-green solid was then centrifuged out and washed with THF for 4-5 times. The metalated MOFs were then stored in THF for further uses. bpyv-MOF-CoCl 2 has $54 \%$ solvent weight based on TGA analysis (Figure S5) and $92 \%$ Co-loading with respect to $\mathrm{Zr}$ centers (i.g. total bridging ligands) based on ICP-MS analysis.
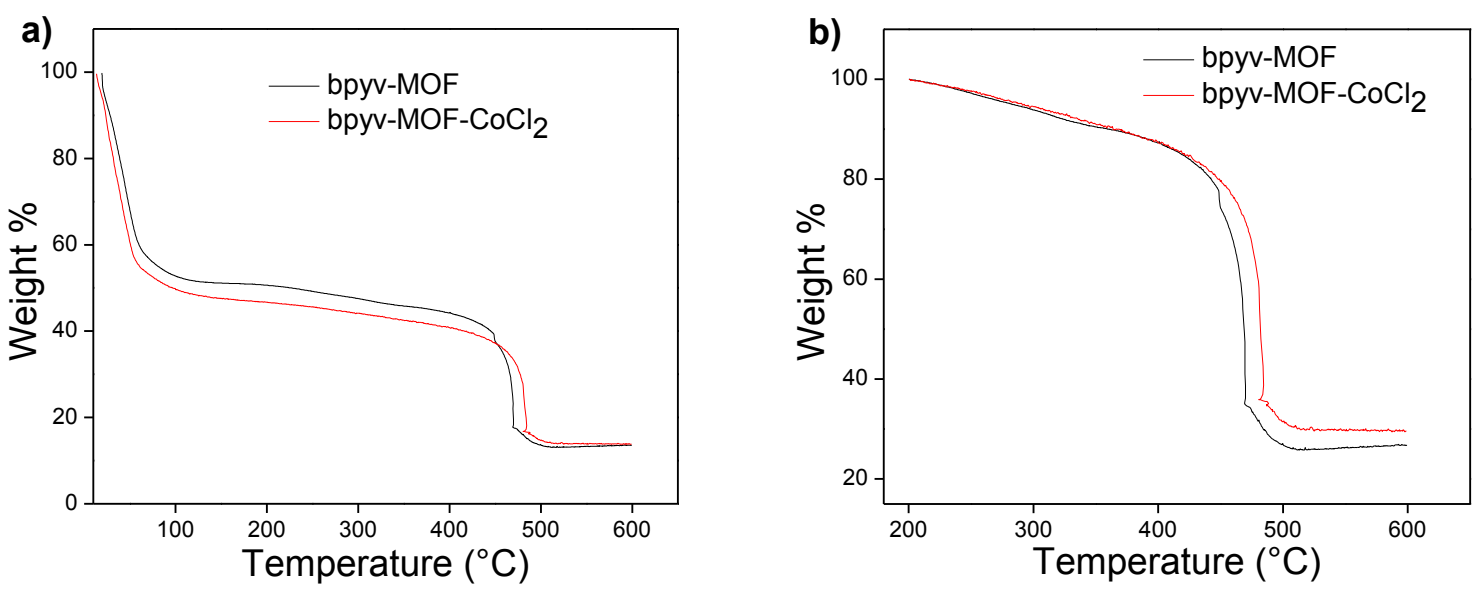

Figure S5. TGA curves of freshly prepared bpyv-MOF (black) and bpyv-MOF-CoCl 2 (red) in the $25-600{ }^{\circ} \mathrm{C}$ range (a) and $200-600{ }^{\circ} \mathrm{C}$ range. (b) The increased residual mass at $600{ }^{\circ} \mathrm{C}$ is due to the presence of $\mathrm{Co}$ in bpyv-MOF-CoCl 2. 

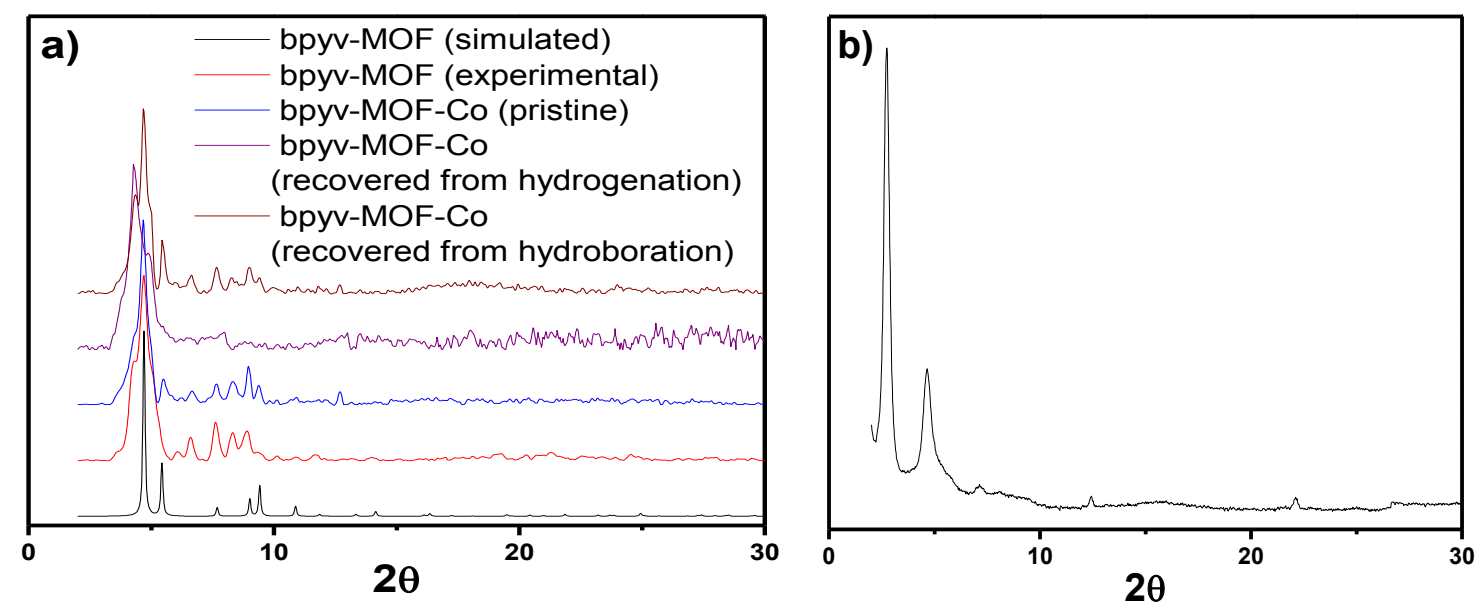

Figure S6. a) PXRD patterns of bpyv-MOF (red), bpyv-MOF-CoCl 2 (blue) and bpyvMOF-Co recovered after hydrogenation (purple) and hydroboration (brown) reactions comparing against the simulated pattern for bpyv-MOF (black). b) PXRD pattern of desolvated bpyv-MOF.
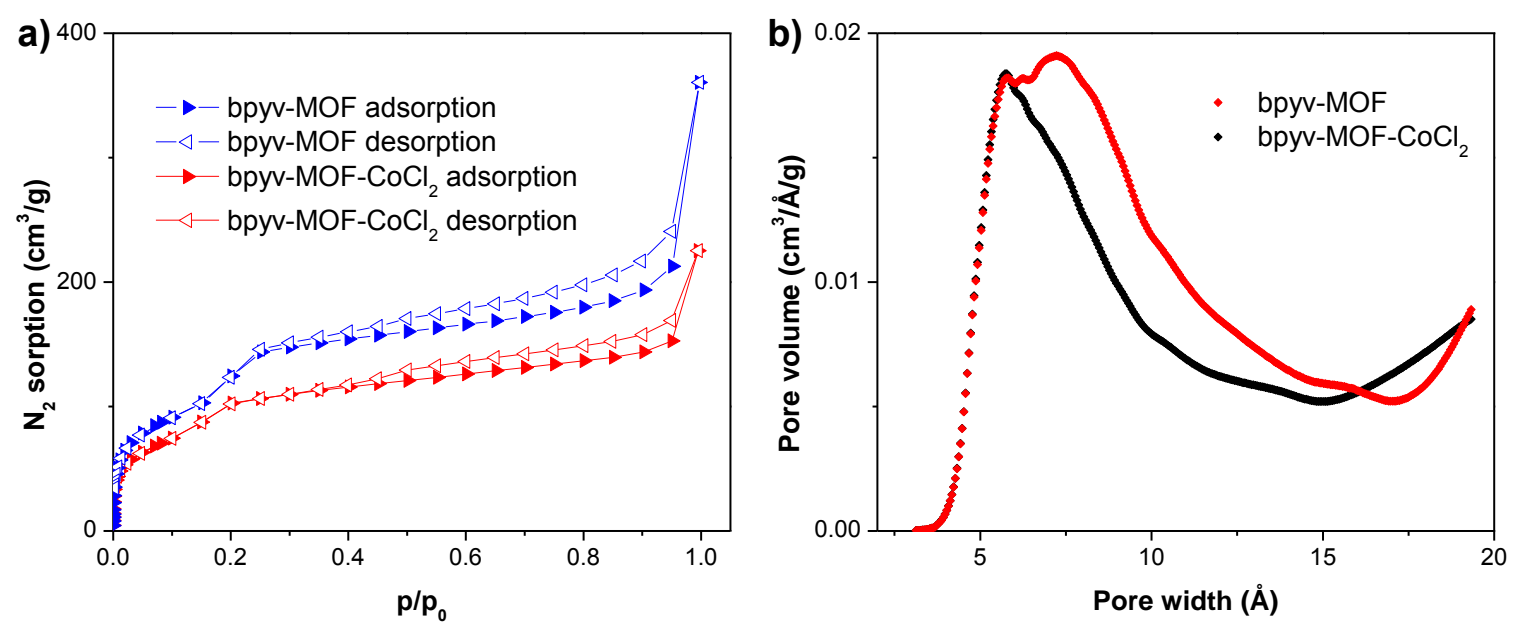

Figure S7. a) Nitrogen sorption isotherm for bpyv-MOF and bpyv-MOF- $\mathrm{CoCl}_{2}$ at $77 \mathrm{~K}$. BET surface areas for bpyv-MOF and bpyv-MOF-CoCl $\mathrm{Cl}_{2}$ are 373 and $294 \mathrm{~m}^{2} / \mathrm{g}$, respectively. b) $\mathrm{HK}$ pore size distribution of bpyv-MOF and bpyv-MOF-CoCl 2 . 


\section{5. mBPP-MOF-CoCl2.}
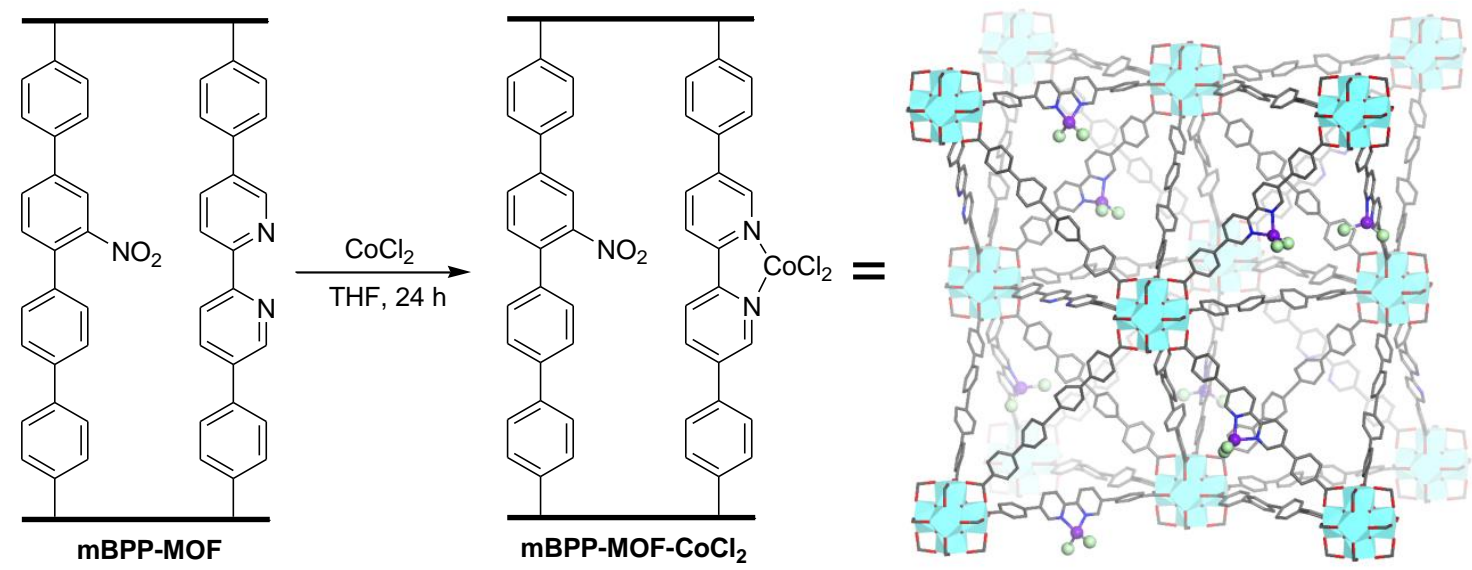

Figure S8. Schematic showing the synthesis and structure of mBPP-MOF-CoCl 2 .

In a glovebox, $\mathrm{CoCl}_{2}(13.0 \mathrm{mg}, 0.10 \mathrm{mmol})$ was dissolved in $10 \mathrm{~mL}$ of $\mathrm{THF}$ in a vial. mBPP-MOF $\left(40.0 \mathrm{mg}\right.$ ) in $\mathrm{THF}$ was added to the $\mathrm{CoCl}_{2}$ solution. The resulting suspension was stirred at room temperature slowly overnight. The resultant blue-green solid was then centrifuged out and washed with THF for 4-5 times. The metalated MOFs were then stored in heptane for further uses. mBPP-MOF-CoCl $\mathrm{Cl}_{2}$ has $31 \%$ solvent weight based on TGA analysis (Figure S9) and 21\% Co-loading with respect to $\mathrm{Zr}$ centers (i.g. total bridging ligands) based on ICP-MS analysis.
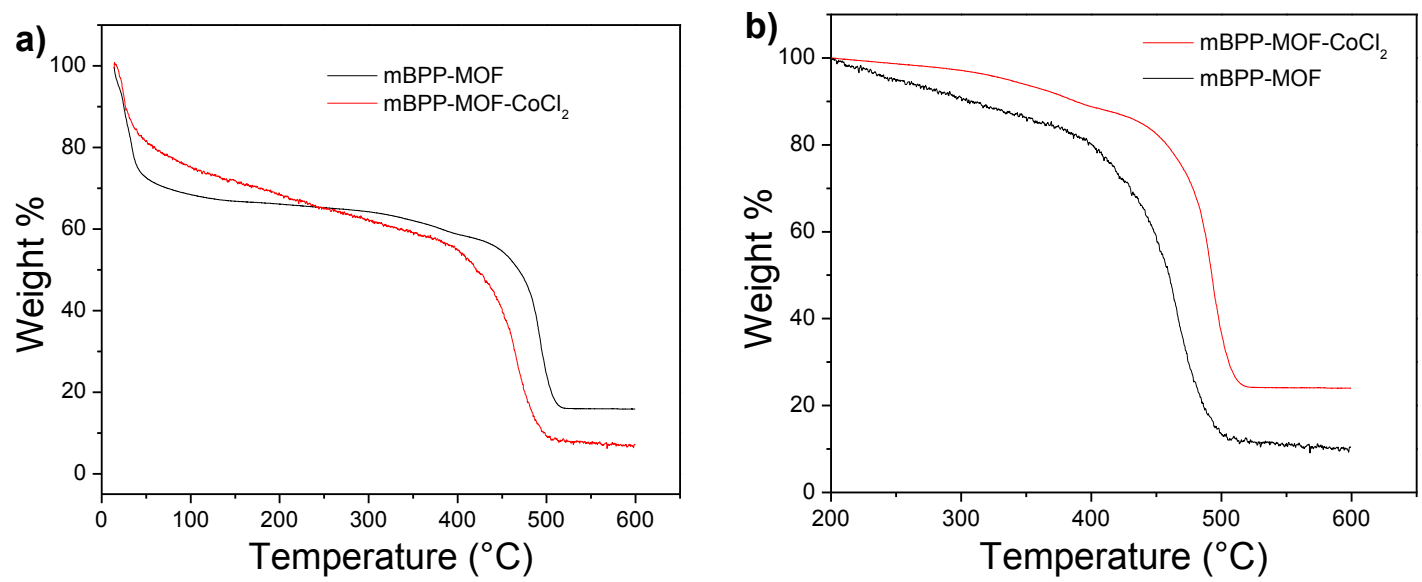

Figure S9. TGA curves of freshly prepared mBPP-MOF (black) and mBPP-MOF-CoCl 2 (red) in the $25-600{ }^{\circ} \mathrm{C}$ range (a) and $200-600{ }^{\circ} \mathrm{C}$ range (b). 

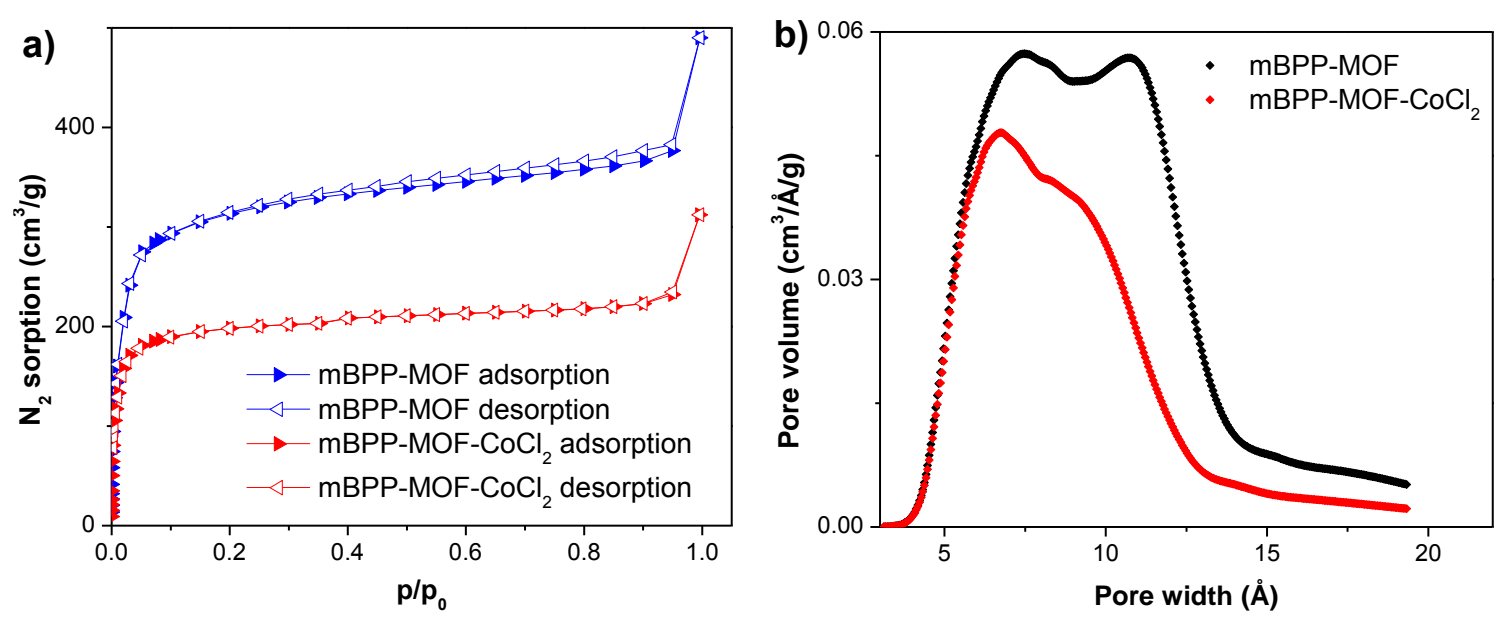

Figure S10. a) Nitrogen sorption isotherms for mBPP-MOF and mBPP-MOF-CoCl 2 at $77 \mathrm{~K}$. BET surface areas for mBPP-MOF and mBPP-MOF-CoCl 2 are 1215 and $768 \mathrm{~m}^{2} / \mathrm{g}$, respectively. b) $\mathrm{HK}$ pore size distribution of $\mathrm{mBPP}-\mathrm{MOF}$ and $\mathrm{mBPP}-\mathrm{MOF}-\mathrm{CoCl} \mathrm{C}_{2}$.

\section{6. mPT-MOF-CoCl2.}
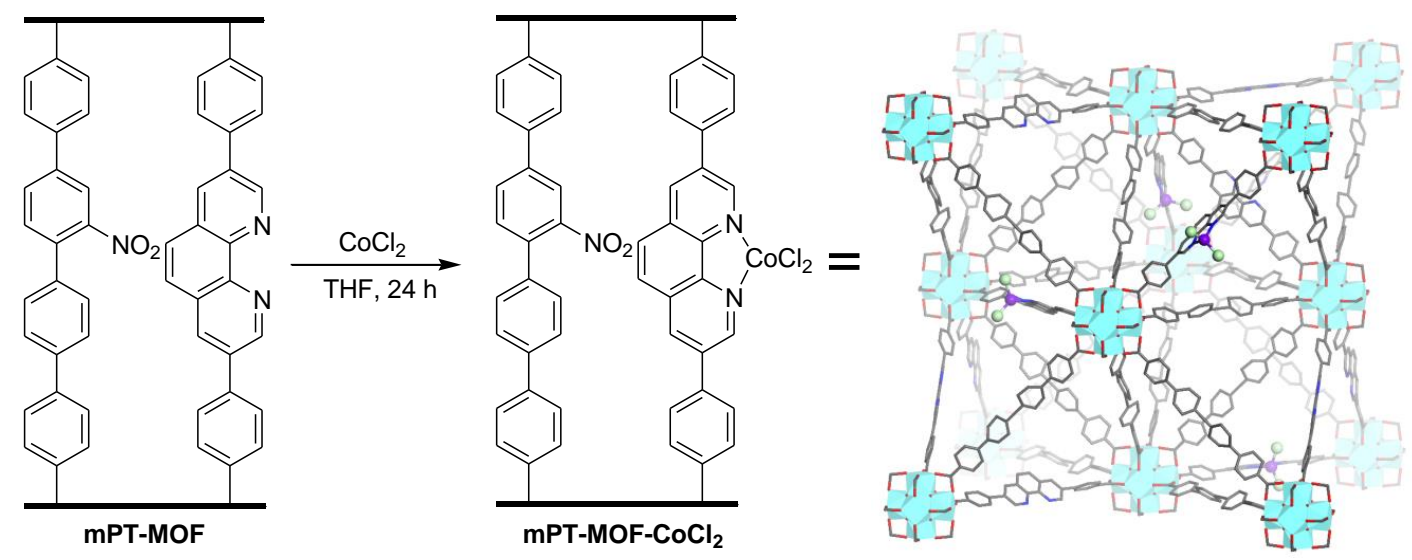

Figure S11. Schematic showing the synthesis and structure of mPT-MOF-CoCl 2 .

In a glovebox, $\mathrm{CoCl}_{2}(8.0 \mathrm{mg}, 0.06 \mathrm{mmol})$ was dissolved in $10 \mathrm{~mL}$ of THF. mPTMOF (30.0 mg) was weighted onto filter paper, washed with THF for several times and added to the $\mathrm{CoCl}_{2}$ solution. The resulting suspension was stirred at room temperature slowly overnight. The resultant blue-green solid was then centrifuged out and washed with THF for 4-5 times. The metalated MOFs were then stored in heptane for further uses. mPT-MOF- $\mathrm{CoCl}_{2}$ has $60 \%$ solvent weight based on TGA analysis (Figure S13) and 12\% 
Co-loading with respect to $\mathrm{Zr}$ centers (i.g. total bridging ligands) based on ICP-MS analysis.

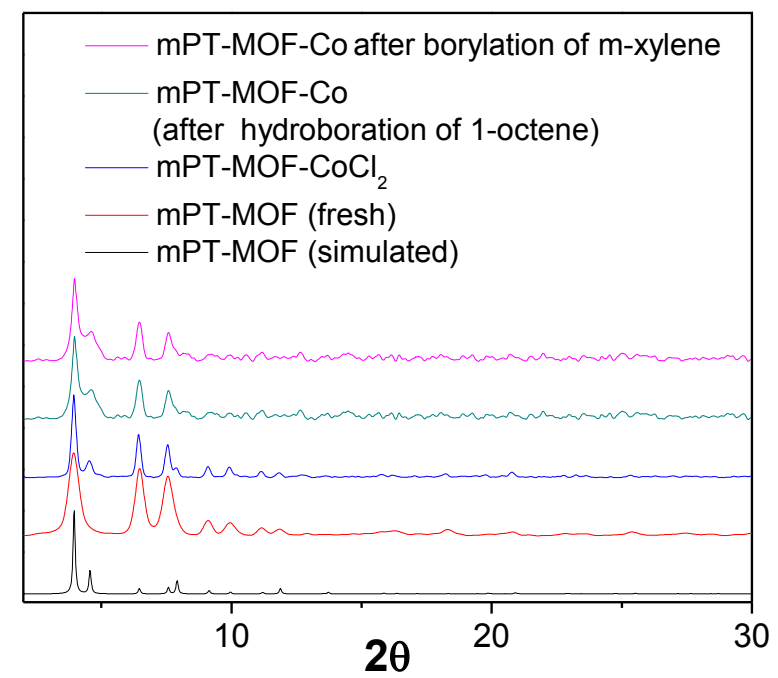

Figure S12. PXRD patterns simulated from CIF file of TPHN-MOF (black), PXRD patterns of mPT-MOF (red), mPT-MOF-CoCl 2 (blue), mPT-MOF-Co recovered from hydroboration of 1octene (green), and mPT-MOF-Co recovered from C-H borylation of $m$-xylene (purple).
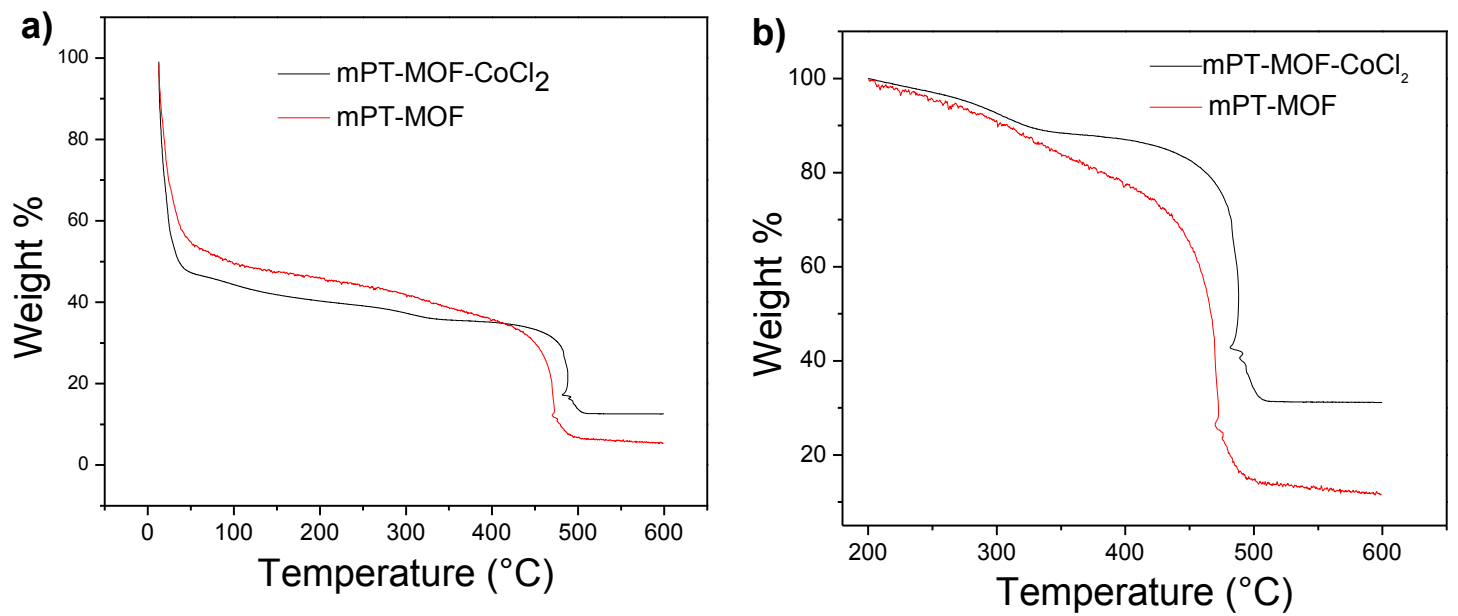

Figure S13. TGA curves of freshly prepared mPT-MOF (black) and mPT-MOF-CoCl 2 (red) in the $25-600{ }^{\circ} \mathrm{C}$ range (a) and $200-600{ }^{\circ} \mathrm{C}$ range. (b) The increased residual mass at $600{ }^{\circ} \mathrm{C}$ is due to the presence of Co in mPT-MOF-CoCl 2 . 

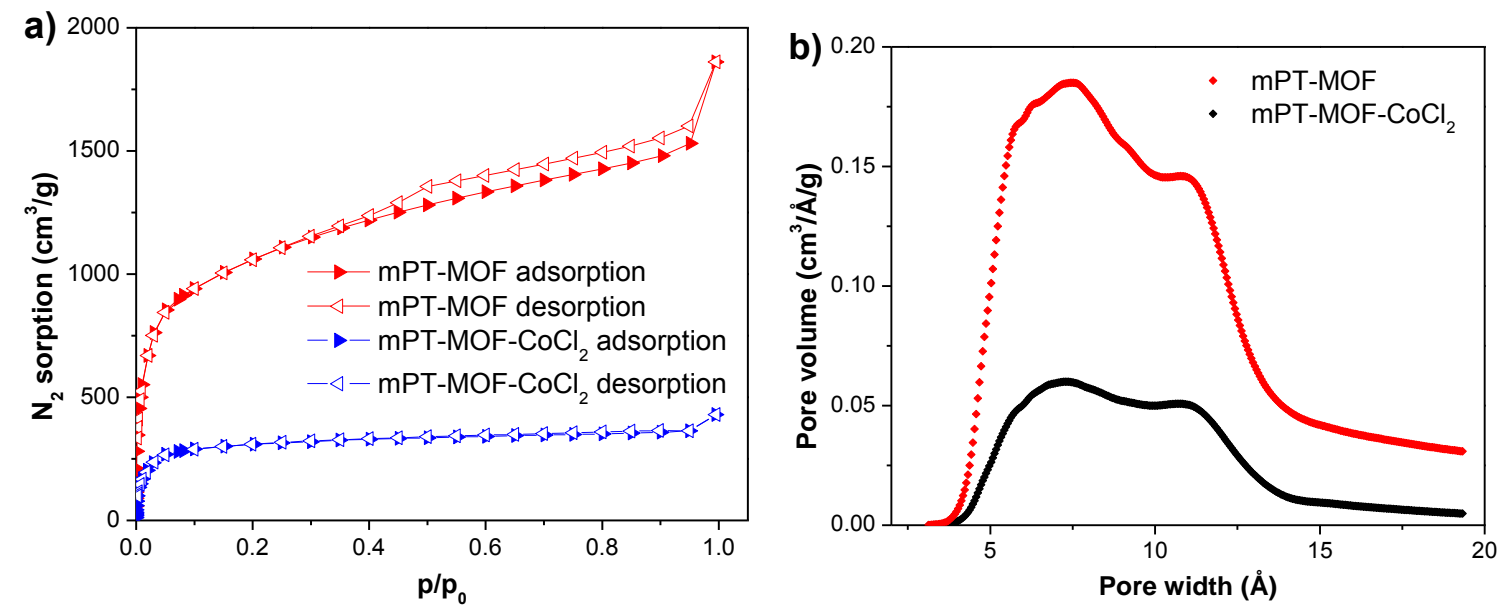

Figure S14. a) Nitrogen sorption isotherms for mPT-MOF and mPT-MOF-CoCl $2(77 \mathrm{~K})$. BET surface areas for mPT-MOF and mPT-MOF-CoCl $\mathrm{C}_{2}$ are 3834 and $1192 \mathrm{~m}^{2} / \mathrm{g}$, respectively. b) $\mathrm{HK}$ pore size distribution of $\mathrm{mPT}-\mathrm{MOF}$ and $\mathrm{mPT}-\mathrm{MOF}-\mathrm{CoCl}_{2}$.

\section{Crystallographic Information and Structural Figures}

Single crystal X-ray diffraction of bpyv-MOF was performed with a Bruker APEX II CCD-based detector at ChemMatCARS (Sector 15), Advanced Photon Source (APS), Argonne National Laboratory. The frames were integrated with the Bruker SAINTC build in APEX II software package using a narrow-frame integration algorithm, which also corrects for the Lorentz and polarization effects. Absorption corrections were applied using SADABS. Structures were solved by direct methods and refined to convergence by least squares method on $F^{2}$ using the SHELXTL-2013 software suite. ${ }^{5}$

Due to the relatively weak diffraction and low resolution, which is not uncommon for this kind of framework with very large solvent accessible void space, restraints (SIMU and DELU) on displacement parameters, and DFIX for bond lengths are applied. The pyridine ring is constrained to ideal geometry. Non-hydrogen atoms are refined isotropically. SQUEEZE subroutine of the PLATON software suite was applied to remove the scattering from the highly disordered guest molecules. The resulting new HKL4 files were used to further refine the structure.

Single crystal X-ray diffraction of $\mathrm{Co}\left({ }^{\mathrm{Me}} 2 \mathrm{bpy}\right)_{2} \cdot 1 / 3 \mathrm{THF}$ was performed with a Bruker D8 Venture, dual microsource ( $\mathrm{Cu}$ and $\mathrm{Mo}$ ) diffractometer with a CMOS detector. Mo K $\alpha$ radiation was used. The frames were integrated with the Bruker SAINT@ build in APEX II software package using a narrow-frame integration algorithm, which also 
corrects for the Lorentz and polarization effects. Absorption corrections were applied using SADABS. Structures were solved by direct methods and refined to convergence by least squares method on $F^{2}$ using the SHELXTL-2013 software suite. ${ }^{5}$ All non-hydrogen atoms are refined anisotropically except for the solvent molecule.

Table S1. Crystallographic information.

\begin{tabular}{|c|c|c|}
\hline Name & bpyv-MOF & $\mathrm{Co}\left({ }^{\mathrm{Me} 2} \mathrm{bpy}\right)_{2} \cdot 1 / 3 \mathrm{THF}$ \\
\hline Formula & $\mathrm{Zr}_{6} \mathrm{O}_{4}(\mathrm{OH})_{4}\left(\mathrm{C}_{16} \mathrm{H}_{12} \mathrm{~N}_{2} \mathrm{O}_{4}\right)_{6}$ & $\mathrm{CoC}_{25.33} \mathrm{H}_{26.67} \mathrm{~N}_{4} \mathrm{O}_{0.33}$ \\
\hline Fw & 2412.91 & 451.44 \\
\hline Temperature (K) & 100 & 100 \\
\hline Wavelength $(\AA)$ & 0.51800 & 0.71073 \\
\hline Crystal system & cubic & monoclinic \\
\hline Space group & $F m \overline{3} m$ & $C 2 / c$ \\
\hline$a, \AA$ & $32.499(7)$ & $25.4633(16)$ \\
\hline$b, \AA$ & $32.499(7)$ & $12.1607(8)$ \\
\hline$c, \AA$ & $32.499(7)$ & $22.1318(14)$ \\
\hline$\alpha,{ }^{\circ}$ & 90 & 90 \\
\hline$\beta,{ }^{\circ}$ & 90 & $107.914(2)$ \\
\hline$\gamma, 0$ & 90 & 90 \\
\hline$V, \AA^{3}$ & $34326(22)$ & $6520.9(7)$ \\
\hline$Z$ & 4 & 12 \\
\hline Density (calcd. $\mathrm{g} / \mathrm{cm}^{3}$ ) & 0.467 & 1.379 \\
\hline Absorption coeff. $\left(\mathrm{mm}^{-1}\right)$ & 0.496 & 0.811 \\
\hline$F(000)$ & 4816 & 2836 \\
\hline$\theta$ range data collection & $0.791-11.520$ & $2.137-30.590$ \\
\hline \multirow[t]{3}{*}{ Limiting indices } & $-25<=\mathrm{h}<=25$ & $-36<=h<=32$ \\
\hline & $-24<=\mathrm{k}<=25$ & $-17<=\mathrm{k}<=17$ \\
\hline & $-23<=1<=25$ & $-31<=1<=31$ \\
\hline Reflection collected & 31759 & 54875 \\
\hline Independent reflections & 473 & 9988 \\
\hline $\mathrm{R}$ (int) & 0.0966 & 0.0895 \\
\hline Data/restraints/parameters & $473 / 23 / 31$ & $9988 / 0 / 411$ \\
\hline Goodness-of-fit on $F^{2}$ & 2.369 & 1.196 \\
\hline Final $R$ indices $[\mathrm{I}>2 \sigma(\mathrm{I})]$ & $\mathrm{R} 1=0.1177, \mathrm{wR} 2=0.2742$ & $\mathrm{R} 1=0.0654, \mathrm{wR} 2=0.1723$ \\
\hline $\mathrm{R}$ indices (all data) & $\mathrm{R} 1=0.1246, \mathrm{wR} 2=0.2770$ & $\mathrm{R} 1=0.1003, \mathrm{wR} 2=0.1895$ \\
\hline
\end{tabular}




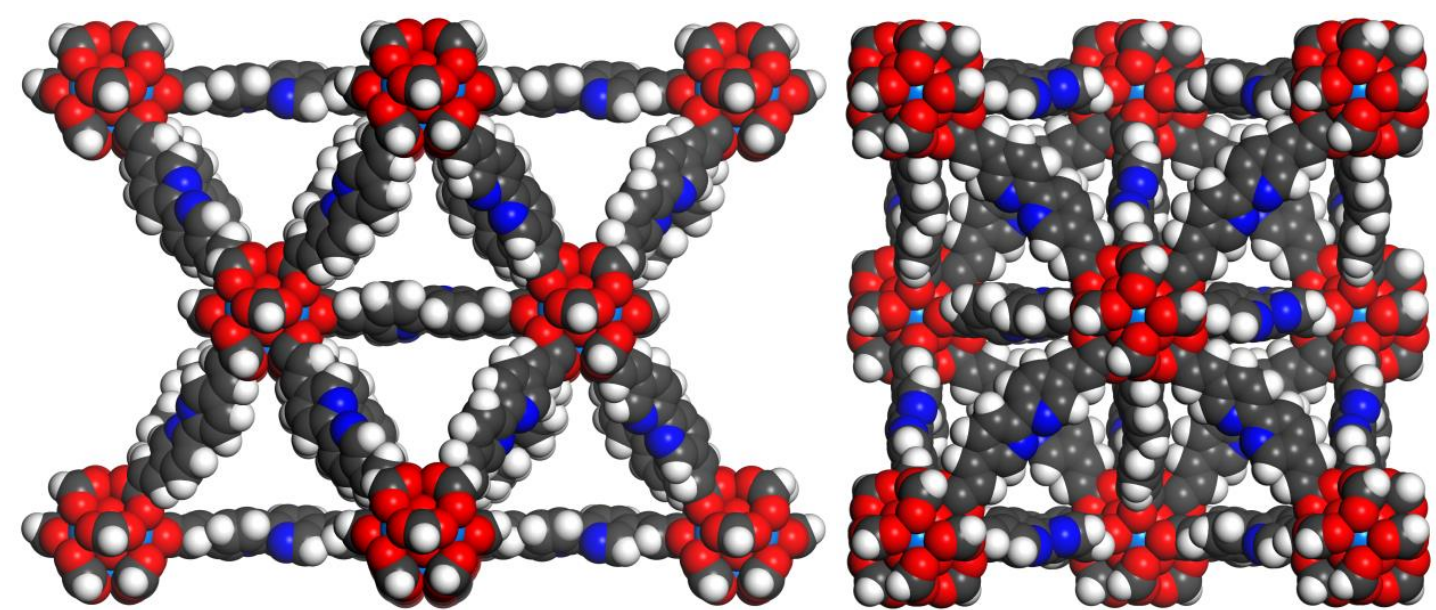

Figure S15. Space-filling model of bpyv-MOF along [110] (left) and [100] (right) directions.

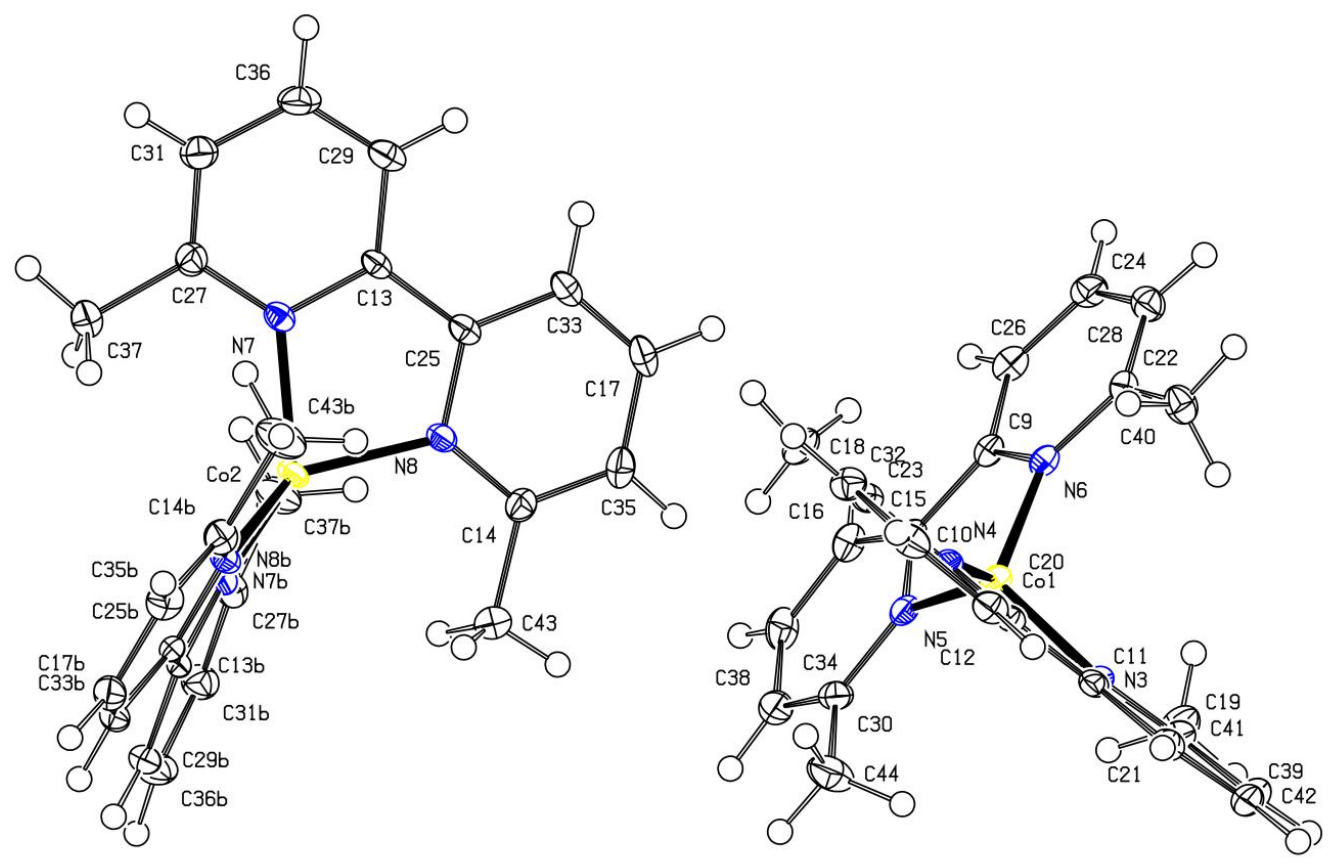

Figure S16. ORTEP of $\mathrm{Co}\left({ }^{\mathrm{Me} 2} \mathrm{bpy}\right)_{2}$ at $50 \%$ probability.

\section{Spectroscopic Characterization of MOF-Co species}

4.1 Synthesis and characterization of homogeneous molecular controls

$\mathrm{Co}\left({ }^{\mathrm{Me} 2}\right.$ bpy $) \mathrm{Cl}_{2}$ was synthesized as reported previously. ${ }^{6}$

Synthesis of Co( $\left.{ }^{\mathrm{Me} 2} \mathbf{b p y}\right) 2 . \mathrm{Co}\left({ }^{\mathrm{Me} 2} \mathrm{bpy}\right) \mathrm{Cl}_{2}(20.0 \mathrm{mg}, 0.063 \mathrm{mmol})$ was suspended in $6 \mathrm{~mL}$ of THF in a nitrogen filled glove box. To the suspension, $0.15 \mathrm{~mL}$ of $\mathrm{NaBEt}_{3} \mathrm{H}(1.0 \mathrm{M}$ in 
THF) (2.5 equiv.) was added and the resulting mixture was stirred for another $15 \mathrm{~min}$. The solution turned deep blue immediately and black precipitate was observed. The solution was then filtered, concentrated and the resulting solid was recrystallized in $\mathrm{THF} /$ diethyl ether at $-30^{\circ} \mathrm{C}$ to afford $12 \mathrm{mg}$ (yield $84 \%$ ) of the product as dark crystal.

Quantification of $\mathrm{H}_{2}$ : Preparation of $\mathrm{Co}\left({ }^{\mathrm{Me} 2} \mathrm{bpy}\right)_{2}$ was carried out in benzene in a septum-sealed vial with $4.8 \mathrm{mg}$ of $\mathrm{Co}\left({ }^{\mathrm{Me} 2} \mathrm{bpy}\right) \mathrm{Cl}_{2}(15.3 \mu \mathrm{mol})$ and $0.04 \mathrm{~mL}$ of $\mathrm{NaBEt}_{3} \mathrm{H}$ solution (1.0 M in toluene, 2.5 equiv.). The headspace gas (total volume $3.50 \mathrm{~mL}$ ) was analyzed by gas chromatography after 15 minutes to give a hydrogen content of $9.6 \%$ $(\mathrm{v} / \mathrm{v})$. The total amount of hydrogen in the headspace was then calculated to be:

$3.50 \mathrm{~mL} \times \frac{9.6}{90.4} \times 101 \mathrm{kPa} \div 8.314 \mathrm{~J} \cdot \mathrm{mol}^{-1} \cdot \mathrm{K}^{-1} \div 295 \mathrm{~K}=15.3 \mu \mathrm{mol}$

This amount of hydrogen is exactly 1 equiv. with respect to the $\mathrm{Co}\left({ }^{\mathrm{Me} 2} \mathrm{bpy}\right) \mathrm{Cl}_{2}$ starting material.

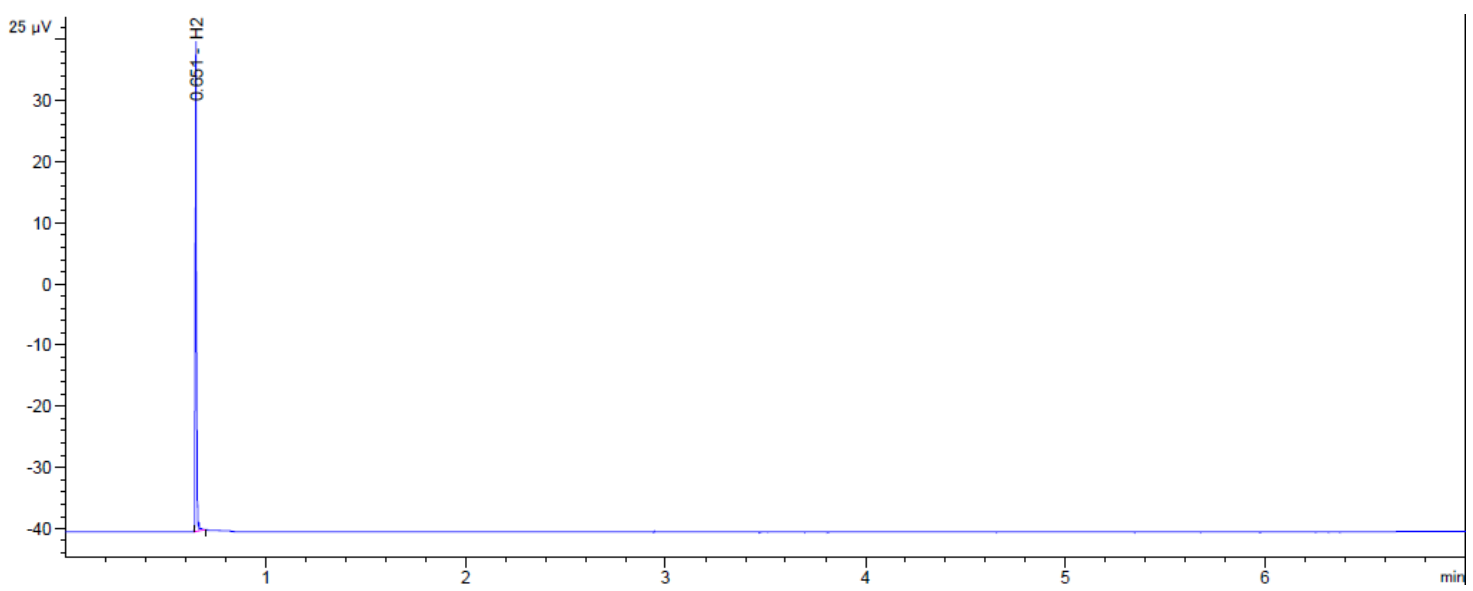

Figure S17. GC trace of the headspace gas. 


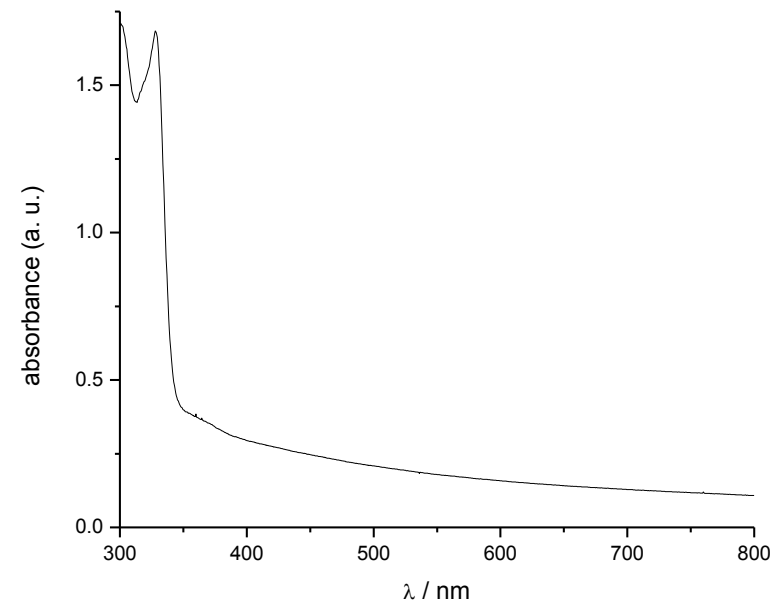

Figure S18. UV-vis spectrum of Co nanoparticles prepared by mixing $\mathrm{CoCl}_{2}$ and $\mathrm{NaBEt}_{3} \mathrm{H}$ in THF.

\subsection{Characterization of MOF-Co species}

Quantification of $\mathbf{H}_{2}$ : In a nitrogen-filled glove box, bpyv-MOF-CoCl $2(12.0 \mathrm{mg}, 6$ $\mu \mathrm{mol} \mathrm{Co})$ in $1.0 \mathrm{~mL}$ benzene was charged into a glass vial with septum. $\mathrm{NaBEt}_{3} \mathrm{H}(20 \mu \mathrm{L}$, 1.0 $\mathrm{M}$ in toluene) was then added to the vial. The headspace gas (total volume $3.70 \mathrm{~mL}$ ) was analyzed by gas chromatography after 15 minutes to give a hydrogen content of $6.7 \%$ $(\mathrm{v} / \mathrm{v})$. The total amount of hydrogen in the headspace was then calculated to be:

$3.70 \mathrm{~mL} \times \frac{6.7}{93.3} \times 101 \mathrm{kPa} \div 8.314 \mathrm{~J} \cdot \mathrm{mol}^{-1} \cdot \mathrm{K}^{-1} \div 295 \mathrm{~K}=10.9 \mu \mathrm{mol}$

This amount is approximately 2 equiv. with respect to Co. The amount of hydrogen is consistent with the sum of reductive elimination from Co center and deprotonation of the SBU protons.

Trapping the bpy-Co(solvent)2 species with $2,2^{\prime}$ '-bipyridine. In a nitrogen-filled glove box, bpyv-MOF- $\mathrm{CoCl}_{2}(1.0 \mathrm{mg})$ in $1.0 \mathrm{~mL}$ benzene was charged into a glass vial. $\mathrm{NaBEt}_{3} \mathrm{H}(10 \mu \mathrm{L}, 1.0 \mathrm{M}$ in THF) was then added to the vial and the mixture was stirred for 15 min. 2,2'-bipyridine (0.6 mg, 2 equiv. w.r.t. Co) was then added, the mixture stirred for another $30 \mathrm{~min}$ and washed with benzene for 3-4 times. The MOF was then quickly dried and digested with $\mathrm{K}_{3} \mathrm{PO}_{4} / \mathrm{D}_{2} \mathrm{O} / \mathrm{DMSO}-d_{6}$ and analyzed by ${ }^{1} \mathrm{H}$ NMR. Comparing the peaks corresponding to $\mathrm{H}_{2}$ bpyv and 2,2'-bipyridyl gives 1:1 molar ratio of 
the two compounds in the digested sample. Control experiments using bpyv-MOF without metalation showed no 2,2'-bipyridyl peaks, excluding the possibility of simply adsorbing or trapping 2,2'-bipyridyl in the MOF channels without coordination bonding.

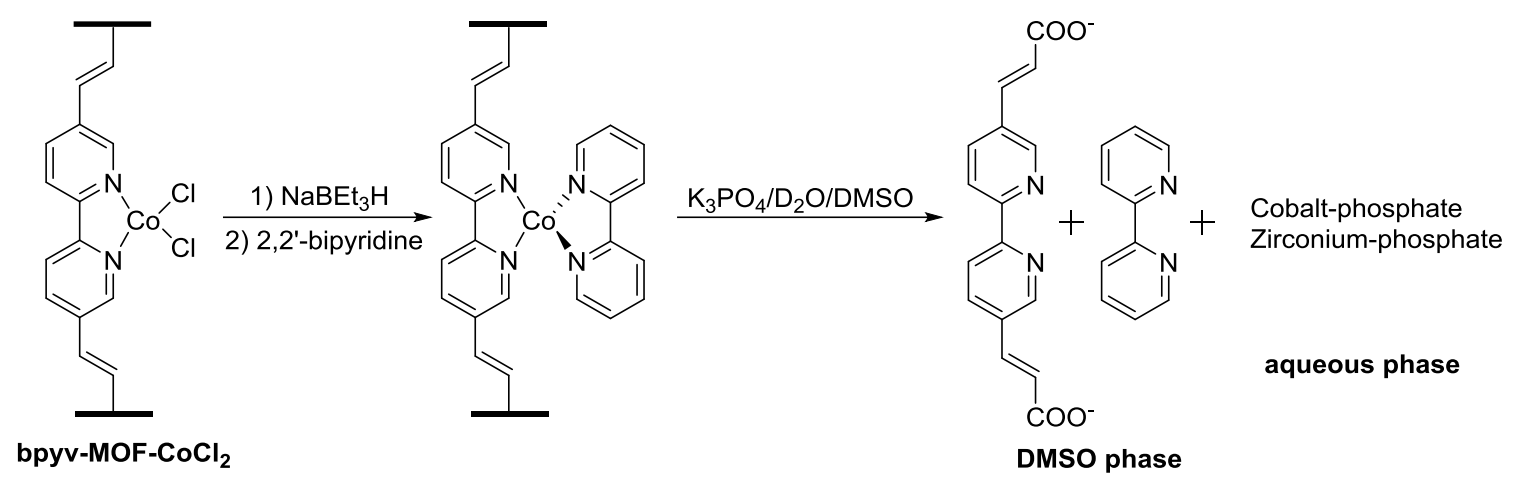

Figure S19. Schematic equation showing the trapping and analysis of 2,2'-bipyridyl coordinated with Co within bpyv-MOF.

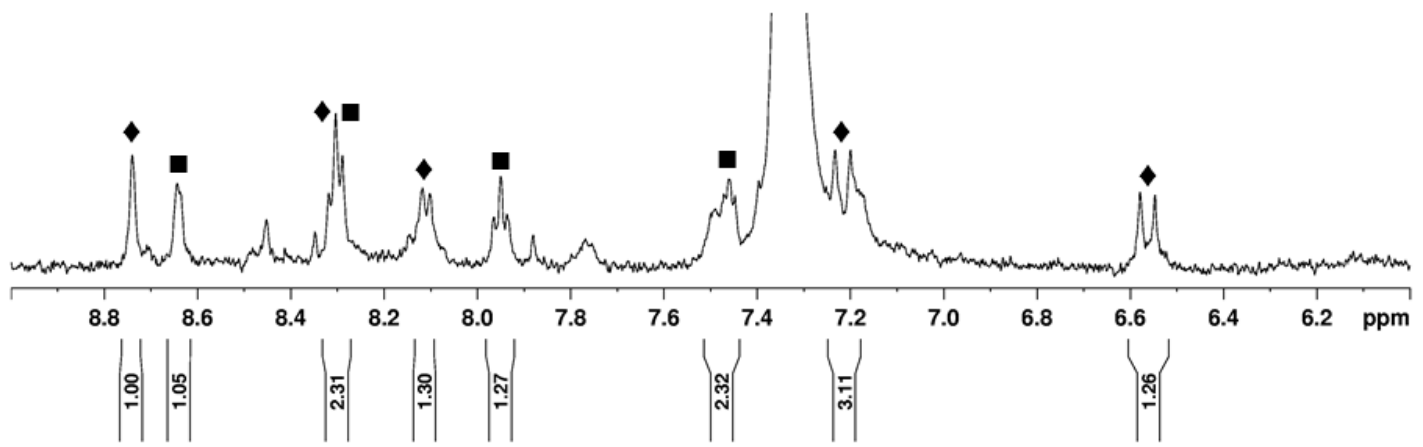

Figure S20. ${ }^{1} \mathrm{H}$ NMR spectrum of bpyv-MOF-Co(bpy) digested in $\mathrm{K}_{3} \mathrm{PO}_{4} / \mathrm{D}_{2} \mathrm{O} / \mathrm{DMSO}-$ $d_{6}$. Peaks are assigned to the bpyv ligand ( $\bullet$ ) and bipyridine ligand ( $\left.\mathbf{}\right)$.

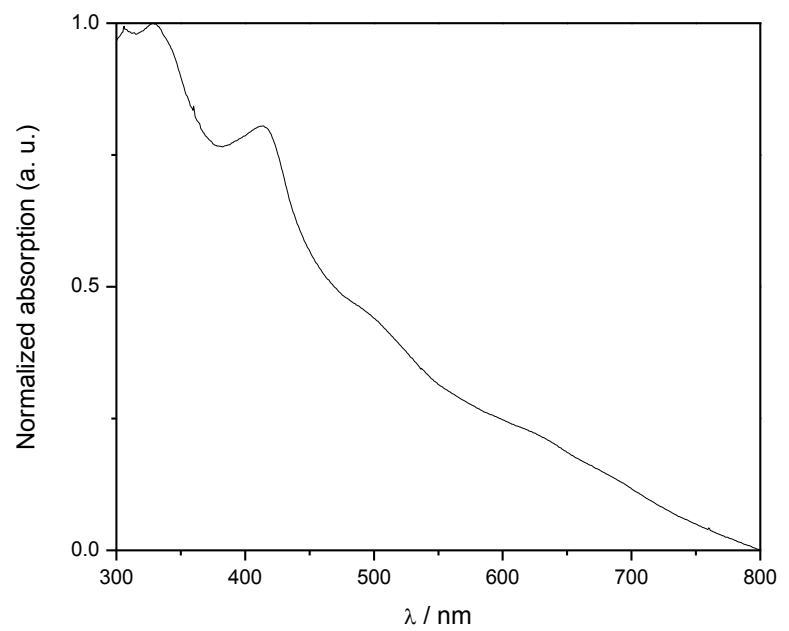

Figure S21. UV-vis absorption spectrum of bpyv-MOF after treating with $\mathrm{NaBEt}_{3} \mathrm{H}$. 


\subsection{Catalysis with the bipyridine-trapped MOF-Co species.}

2,2'-bipyridine-trapped mBPP-MOF-Co was synthesized similar to bipyridinetrapped bpyv-MOF-Co as described above and used for catalytic alkene hydrogenation and hydroboration. In hydrogenation of styrene at $23{ }^{\circ} \mathrm{C}$, the initial rates for bipyridinetrapped mBPP-MOF-Co and the original catalyst mBPP-MOF-Co were $3.3 \times 10^{-3}$ and $5.0 \times 10^{-4} \mathrm{M} / \mathrm{s}$, respectively $\left.\left([\mathrm{Co}]=6.85 \times 10^{-5} \mathrm{M} \text {; [styrene }\right]_{\text {initial }}=5.82 \mathrm{M}, p_{\mathrm{H} 2}=40 \mathrm{bar}\right)$. This experiment shows mBPP-MOF-Co at least 6 times more active compared to the analogous bipyridine-trapped mBPP-MOF-Co catalyst.

In hydroboration of 1-octene, the reaction conditions are similar to those of Entry 1, Table 2 ( $0.1 \%$ Co loading, 1.3 equiv HBpin, $18 \mathrm{~h}, \mathrm{rt})$. In case of bipyridine-trapped bpyv-MOF-Co-catalyzed hydroboration, only 5\% conversion of 1-octene was observed. In contrast, under identical reaction conditions, bpyv-MOF-Co gave 66\% conversion. bpyv-MOF-Co is thus at least 13 times more active than bipyridine-trapped bpyv-MOFCo.

\subsection{Control experiments with surface trapped species.}

To demonstrate the effects of any surface trapped species, we performed control experiments with a MOF (bphv-MOF) built from the unfunctionalized 3,3'-(biphenyl4,4'-diyl)diacrylic acid linker, ${ }^{1}$ and treated it in the same way as bpyv-MOF (Figure S22). Although significant amounts of Co was detected by ICP-MS (Co: $\mathrm{Zr}=0.09: 1)$, the resulting solid was found to be inactive for hydrogenation of styrene under the same loading of MOFs while $0.01 \%$ bpyv-MOF-Co gave complete conversion. Additionally, UV-vis spectrum of that solid did not show any absorption peak at the visible to near infrared region. These observations thus proved that the surface trapped nanoparticles contribute little, if any, to the catalytic activity of the MOF catalyst. 


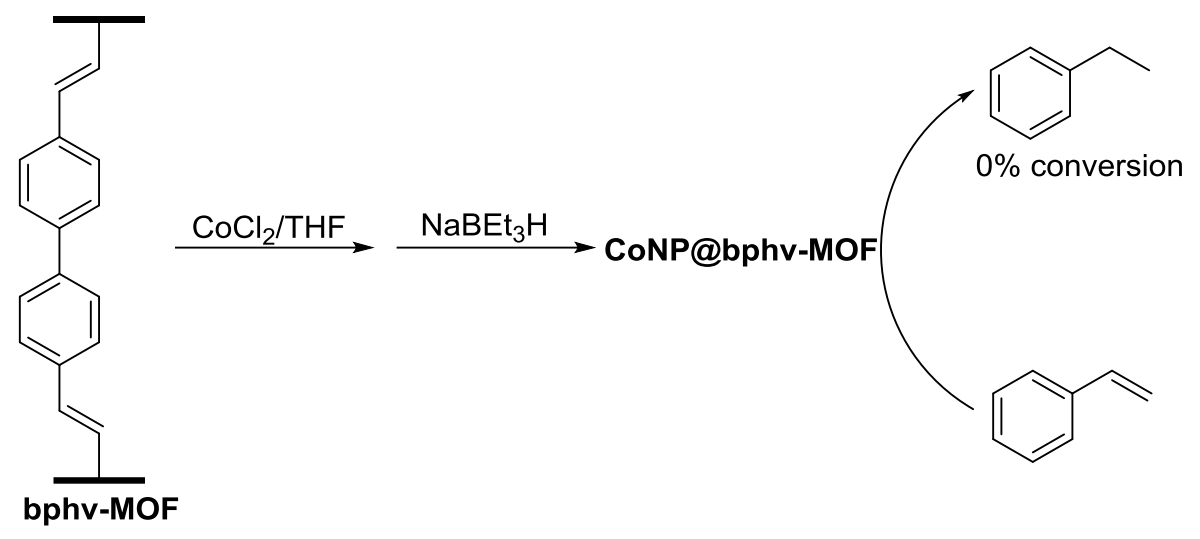

Figure S22. Control experiments with surface trapped species.

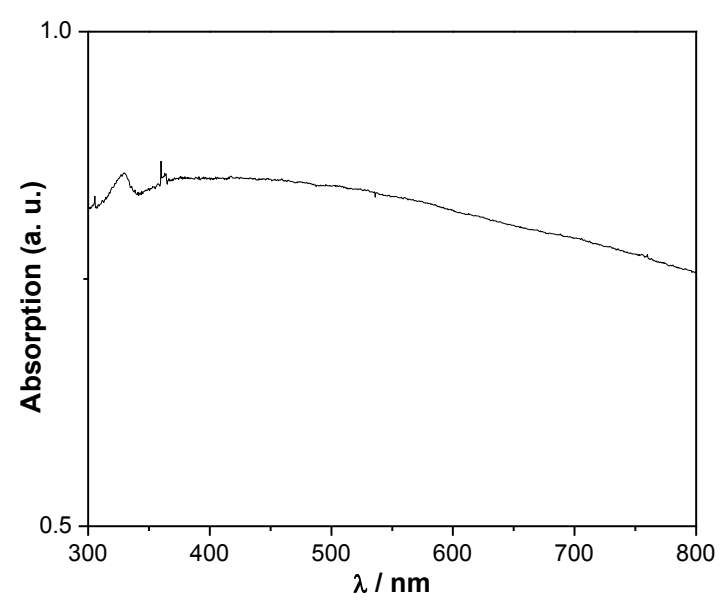

Figure S23. UV-vis absorption spectrum of CoNP@bphv-MOF.

\section{X-Ray Absorption Spectroscopic Analysis.}

\subsection{Data collection.}

X-ray absorption data were collected at Beamline 9-BM-C at the Advanced Photon Source (APS) at Argonne National Laboratory. Spectra were collected at the iron or cobalt K-edge in transmission mode. The X-ray beam was monochromatized by a Si(111) monochromater and detuned by $25 \%$ to minimize harmonics. A metallic iron or cobalt foil standard was used as the reference for energy calibration and was measured simultaneously with experimental samples. The incident beam intensity $\left(I_{0}\right)$ was measured by an ionization chamber with $30 \% \mathrm{~N}_{2}$ and $70 \%$ He gas composition. Data was collected in three regions: a pre-edge region -150 to $-20 \mathrm{eV}$ ( $5 \mathrm{eV}$ step size, dwell time $1.0 \mathrm{~s})$, XANES region - 20 to $50 \mathrm{eV}(0.5 \mathrm{eV}$ step size, dwell time $1.0 \mathrm{~s})$, and EXAFS region $3.62 \AA^{-1}$ to $13.93 \AA^{-1}\left(0.05 \AA^{-1}\right.$ step size, dwell time increased linearly from 1.0 
to 3.9 seconds over the region to facilitate higher k-weighted data processing). All energies are listed relative to the elemental Co K-edge (7709 eV). Multiple X-ray absorption spectra were collected at room temperature for each sample. Samples were grinded and mixed with polyethyleneglycol (PEG) and packed in a 6-shooter sample holder to achieve adequate absorption length.

\subsection{Data processing.}

Data were processed using the Athena and Artemis programs of the IFEFFIT package based on FEFF $6 .^{7,8}$ Prior to merging, spectra were calibrated against the reference spectra (metallic Co) and aligned to the first peak in the smoothed first derivative of the absorption spectrum, background removed, and spectra processed to obtain a normalized unit edge step.

\subsection{XANES analysis.}

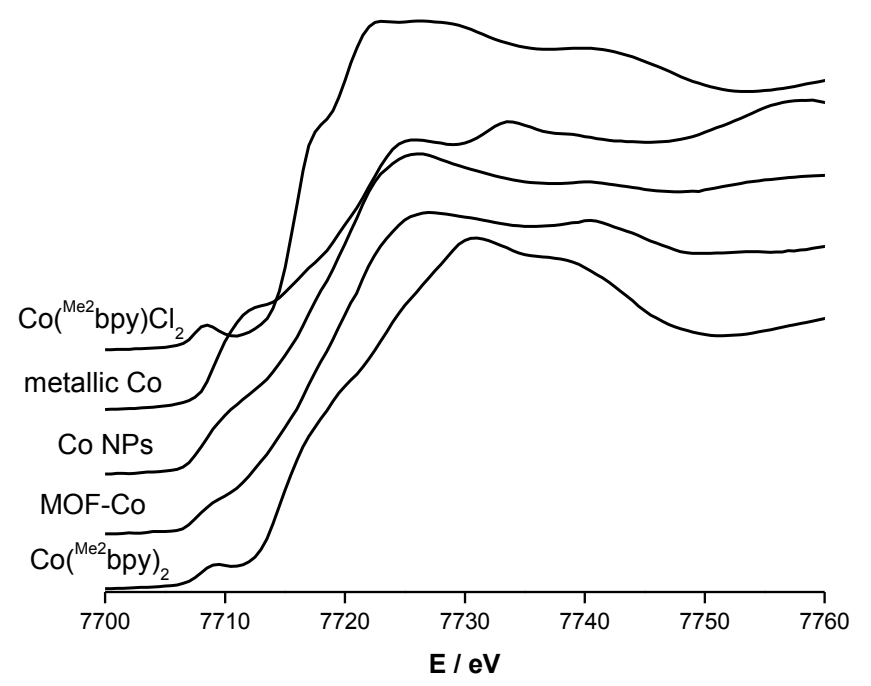

Figure S24. XANES spectra of $\left.\mathrm{Co}^{\mathrm{Me} 2} \mathrm{bpy}\right)_{2}$, bpyv-MOF-Co, Co nanoparticles, metallic $\mathrm{Co}$, and $\mathrm{Co}\left({ }^{\mathrm{Me} 2} \mathrm{bpy}\right) \mathrm{Cl}_{2}$.

The XANES spectra in Figure S24 show that Co K-edge positions of bpyv-MOF-Co and $\mathrm{Co}\left({ }^{\mathrm{Me} 2} \mathrm{bpy}\right)_{2}$ are close to $\mathrm{Co}\left({ }^{\mathrm{Me} 2} \mathrm{bpy}\right) \mathrm{Cl}_{2}$, indicating higher actual oxidation states for the Co centers than formally-assigned zero. Similar behaviors have been observed for other low-valence transition metal complexes with redox non-innocent ligands. ${ }^{9}$ It is also worth 
noting here that the position of rising edge is the result of numerous superimposing features being affected by various factors and can be attributed to multiple processes including $1 \mathrm{~s}-4 \mathrm{p}$ and $1 \mathrm{~s}$-ligand $\pi^{*}$ transitions. Giving this complexity, assigning oxidation states and edge transitions become ambiguous.

\subsection{EXAFS fitting.}

Fits of the EXAFS region were performed using the Artemis program of the IFEFFIT package. Fits were performed with a $k$-weight of 3 in $R$-space. Refinement was performed by optimizing an amplitude factor $S_{0}^{2}$ and energy shift $\Delta E_{0}$ which are common to all paths, in addition to parameters for bond length $(\Delta R)$ and Debye-Waller factor $\left(\sigma^{2}\right)$. The crystal structures for $\mathrm{Co}\left({ }^{\mathrm{Me} 2} \mathrm{bpy}\right) \mathrm{Cl}_{2}$ and $\mathrm{Co}\left({ }^{\mathrm{Me}} 2 \mathrm{bpy}\right)_{2}$ were used to fit the EXAFS data for the molecular compounds as well as the MOFs, assuming a similar local coordination environment around the metal centers in the complex and MOFs. Unique parameters for $\Delta R$ and $\sigma^{2}$ were provided for all scattering paths in all fits. The amplitude factors $S_{0}^{2}$ for bpy-MOF-CoCl 2 and bpyv-MOF-CoCl $\mathrm{C}_{2}$ were set equal to that obtained from the fits of the corresponding molecular compounds.

Table S2. Summary of EXAFS fitting parameters for $\mathrm{Co}\left({ }^{\mathrm{Me} 2} \mathrm{bpy}\right) \mathrm{Cl}_{2}$, bpy-MOF-CoCl $\mathrm{C}_{2}$, and bpyv-MOF-CoCl 2 .

\begin{tabular}{|l|l|l|l|}
\hline Sample & $\mathrm{Co}\left({ }^{\mathrm{Me} 2} \mathrm{bpy}\right) \mathrm{Cl}_{2}$ & bpy-MOF-CoCl & \\
\hline Fitting range & $k 3.00-13.62 \AA^{-1}$ & $k 3.00-11.98 \AA^{-1}$ & $k 3.00-11.84 \AA^{-1}$ \\
& $R 1-4.5 \AA$ & $R 1-4.5 \AA$ & $R 1-4.5 \AA$ \\
\hline Independent points & 23 & 19 & 19 \\
\hline Variables & 12 & 11 & 11 \\
\hline R-factor & 0.011 & 0.012 & 0.013 \\
\hline$S_{0}^{2}$ & $1.092 \pm 0.097$ & 1.092 (fixed $)$ & 1.092 (fixed $)$ \\
\hline$\Delta E_{0}(\mathrm{eV})$ & $3.93 \pm 1.76$ & $-0.33 \pm 2.29$ & $-1.11 \pm 2.56$ \\
\hline$R(\mathrm{Co}-\mathrm{N})(\AA)$ & $2.05 \pm 0.02$ & $2.06 \pm 0.04$ & $2.03 \pm 0.04$ \\
\hline$\sigma^{2}(\mathrm{Co}-\mathrm{N})\left(\AA^{2}\right)$ & $0.0070 \pm 0.0026$ & $0.0120 \pm 0.0026$ & $0.0114 \pm 0.0022$ \\
\hline$R(\mathrm{Co}-\mathrm{Cl})(\AA)$ & $2.23 \pm 0.01$ & $2.29 \pm 0.01$ & $2.29 \pm 0.02$ \\
\hline$\sigma^{2}(\mathrm{Co}-\mathrm{Cl})\left(\AA^{2}\right)$ & $0.0046 \pm 0.0007$ & $0.0073 \pm 0.0008$ & $0.0077 \pm 0.0008$ \\
\hline$R(\mathrm{Co}-\mathrm{C} 2)(\AA)$ & $2.94 \pm 0.04$ & $2.73 \pm 0.03$ & $2.73 \pm 0.06$ \\
\hline$\sigma^{2}(\mathrm{Co}-\mathrm{C} 2)\left(\AA^{2}\right)$ & $0.0089 \pm 0.0056$ & $0.0044 \pm 0.0019$ & $0.0079 \pm 0.0035$ \\
\hline$R(\mathrm{Co}-\mathrm{C} 6)\left(\AA^{2}\right)$ & $3.17 \pm 0.10$ & $2.96 \pm 0.03$ & $2.96 \pm 0.05$ \\
\hline$\sigma^{2}(\mathrm{Co}-\mathrm{C} 6)\left(\AA^{2}\right)$ & $0.0165 \pm 0.0167$ & $0.0056 \pm 0.0034$ & $0.0078 \pm 0.0050$ \\
\hline
\end{tabular}




\begin{tabular}{|l|l|l|l|}
\hline$R(\mathrm{Co}-\mathrm{C} 2-\mathrm{C} 3)(\AA)$ & $4.31 \pm 0.04$ & $4.34 \pm 0.05$ & $4.33 \pm 0.05$ \\
\hline$\sigma^{2}(\mathrm{Co}-\mathrm{C} 2-\mathrm{C} 3)\left(\AA^{2}\right)$ & $0.0079 \pm 0.0048$ & $0.0103 \pm 0.0056$ & $0.0103 \pm 0.0055$ \\
\hline
\end{tabular}

Table S3. Summary of EXAFS fitting parameters for mPT-MOF-CoCl 2 and mBPP$\mathrm{MOF}-\mathrm{CoCl}_{2}$.

\begin{tabular}{|l|l|l|}
\hline Sample & $\mathrm{mPT}-\mathrm{MOF}-\mathrm{CoCl}_{2}$ & $\mathrm{mBPP}-\mathrm{MOF}-\mathrm{CoCl}_{2}$ \\
\hline Fitting range & $k 3.00-11.90 \AA^{-1}$ & $k 3.00-11.90 \AA^{-1}$ \\
& $R 1-4.5 \AA$ & $R 1.2-4.5 \AA$ \\
\hline Independent points & 19 & 18 \\
\hline Variables & 12 & 12 \\
\hline $\mathrm{R}-$ factor & 0.034 & 0.010 \\
\hline$S_{0}^{2}$ & $1.056 \pm 0.071$ & $1.055 \pm 0.098$ \\
\hline$\Delta E_{0}(\mathrm{eV})$ & $-7.32 \pm 3.49$ & $-0.58 \pm 2.35$ \\
\hline$R(\mathrm{Co}-\mathrm{N})(\AA)$ & $1.96 \pm 0.04$ & $2.06 \pm 0.02$ \\
\hline$\sigma^{2}(\mathrm{Co}-\mathrm{N})\left(\AA^{2}\right)$ & $0.0080 \pm 0.0031$ & $0.0070 \pm 0.0022$ \\
\hline$R(\mathrm{Co}-\mathrm{Cl})(\AA)$ & $2.23 \pm 0.02$ & $2.28 \pm 0.02$ \\
\hline$\sigma^{2}(\mathrm{Co}-\mathrm{Cl})\left(\AA^{2}\right)$ & $0.0059 \pm 0.0011$ & $0.0095 \pm 0.0017$ \\
\hline$R(\mathrm{Co}-\mathrm{C} 2)(\AA)$ & $2.96 \pm 0.03$ & $2.76 \pm 0.04$ \\
\hline$\sigma^{2}(\mathrm{Co}-\mathrm{C} 2)\left(\AA^{2}\right)$ & $0.0008 \pm 0.0019$ & $0.0058 \pm 0.0026$ \\
\hline$R(\mathrm{Co}-\mathrm{C} 6)(\AA)$ & $3.35 \pm 0.04$ & $2.98 \pm 0.03$ \\
\hline$\sigma^{2}(\mathrm{Co}-\mathrm{C} 6)\left(\AA^{2}\right)$ & $0.0011 \pm 0.0024$ & $0.0030 \pm 0.0022$ \\
\hline$R(\mathrm{Co}-\mathrm{C} 2-\mathrm{C} 3)(\AA)$ & $4.22 \pm 0.05$ & $4.33 \pm 0.04$ \\
\hline$\sigma^{2}(\mathrm{Co}-\mathrm{C} 2-\mathrm{C} 3)\left(\AA^{2}\right)$ & $0.0048 \pm 0.0049$ & $0.0092 \pm 0.0048$ \\
\hline
\end{tabular}

Table S4. Summary of EXAFS fitting parameters for activated bpyv-MOF-Co.

\begin{tabular}{|l|l|l|l|}
\hline Fitting range & $k 2.44-11.29 \AA^{-1}$ & $R(\mathrm{Co}-\mathrm{C} 6)(\AA)$ & $2.98 \pm 0.08$ \\
\cline { 3 - 4 } & $R 1-4.5 \AA$ & $\sigma^{2}(\mathrm{Co}-\mathrm{C} 6)\left(\AA^{2}\right)$ & $0.0035 \pm 0.0035$ \\
\hline Independent points & 19 & $R(\mathrm{Co}-\mathrm{C} 2-\mathrm{C} 3)(\AA)$ & $4.27 \pm 0.07$ \\
\hline Variables & 16 & $\sigma^{2}(\mathrm{Co}-\mathrm{C} 2-\mathrm{C} 3)\left(\AA^{2}\right)$ & $0.0072 \pm 0.0063$ \\
\hline R-factor & 0.017 & $R(\mathrm{Co}-\mathrm{Co})\left(\AA^{2}\right)$ & $2.45 \pm 0.05$ \\
\hline$S_{0}{ }^{2}$ & $1.050 \pm 0.055$ & $\sigma^{2}(\mathrm{Co}-\mathrm{Co})\left(\AA^{2}\right)$ & $0.0045 \pm 0.0061$ \\
\hline$\Delta E_{0}(\mathrm{eV})$ & $-5.09 \pm 4.75$ & $\mathrm{C} . \mathrm{N} .(\mathrm{Co})$ & $0.95 \pm 0.76$ \\
\hline$R(\mathrm{Co}-\mathrm{N})(\AA)$ & $1.96 \pm 0.04$ & $R\left(\mathrm{Co}-\mathrm{O}_{\mathrm{THF}}\right)(\AA)$ & $2.09 \pm 0.09$ \\
\hline$\sigma^{2}(\mathrm{Co}-\mathrm{N})\left(\AA^{2}\right)$ & $0.0050 \pm 0.0045$ & $\sigma^{2}\left(\mathrm{Co}-\mathrm{O}_{\mathrm{THF}}\right)\left(\AA^{2}\right)$ & $0.0032 \pm 0.0055$ \\
\hline$R(\mathrm{Co}-\mathrm{C} 2)(\AA)$ & $2.62 \pm 0.15$ & $\mathrm{C} . \mathrm{N} .\left(\mathrm{O}_{\text {THF }}\right)$ & $0.47 \pm 1.87$ \\
\hline$\sigma^{2}(\mathrm{Co}-\mathrm{C} 2)\left(\AA^{2}\right)$ & $0.0023 \pm 0.0052$ & & \\
\hline
\end{tabular}

Table S5. Summary of EXAFS fitting parameters for $\mathrm{Co}\left({ }^{\mathrm{Me} 2} \mathrm{bpy}\right)_{2}$.

\begin{tabular}{|l|l|l|l|}
\hline Fitting range & $k 3.00-11.92 \AA^{-1}$ & $R(\mathrm{Co}-\mathrm{C} 2)(\AA)$ & $2.85 \pm 0.02$ \\
\cline { 2 - 4 } & $R 1.3-5 \AA$ & $\sigma^{2}(\mathrm{Co}-\mathrm{C} 2)\left(\AA^{2}\right)$ & $0.0012 \pm 0.0018$ \\
\hline Independent points & 20 & $R(\mathrm{Co}-\mathrm{C} 6)(\AA)$ & $3.06 \pm 0.04$ \\
\hline \multicolumn{2}{|c|}{$\mathrm{S} 20$}
\end{tabular}




\begin{tabular}{|l|l|l|l|}
\hline Variables & 12 & $\sigma^{2}(\mathrm{Co}-\mathrm{C} 6)\left(\AA^{2}\right)$ & $0.0018 \pm 0.0025$ \\
\hline $\mathrm{R}$-factor & 0.031 & $R($ Co-C7 $)(\AA)$ & $3.27 \pm 0.03$ \\
\hline$S_{0}{ }^{2}$ & $0.817 \pm 0.158$ & $\sigma^{2}(\mathrm{Co}-\mathrm{C} 7)\left(\AA^{2}\right)$ & $0.0005 \pm 0.0020$ \\
\hline$\Delta E_{0}(\mathrm{eV})$ & $5.54 \pm 2.60$ & $R(\mathrm{Co}-\mathrm{C} 2-\mathrm{C} 3)(\AA)$ & $4.27 \pm 0.06$ \\
\hline$R(\mathrm{Co}-\mathrm{N})(\AA)$ & $1.96 \pm 0.01$ & $\sigma^{2}(\mathrm{Co}-\mathrm{C} 2-\mathrm{C} 3)\left(\AA^{2}\right)$ & $0.0080 \pm 0.0061$ \\
\hline$\sigma^{2}(\mathrm{Co}-\mathrm{N})\left(\AA^{2}\right)$ & $0.0031 \pm 0.0014$ & & \\
\hline
\end{tabular}

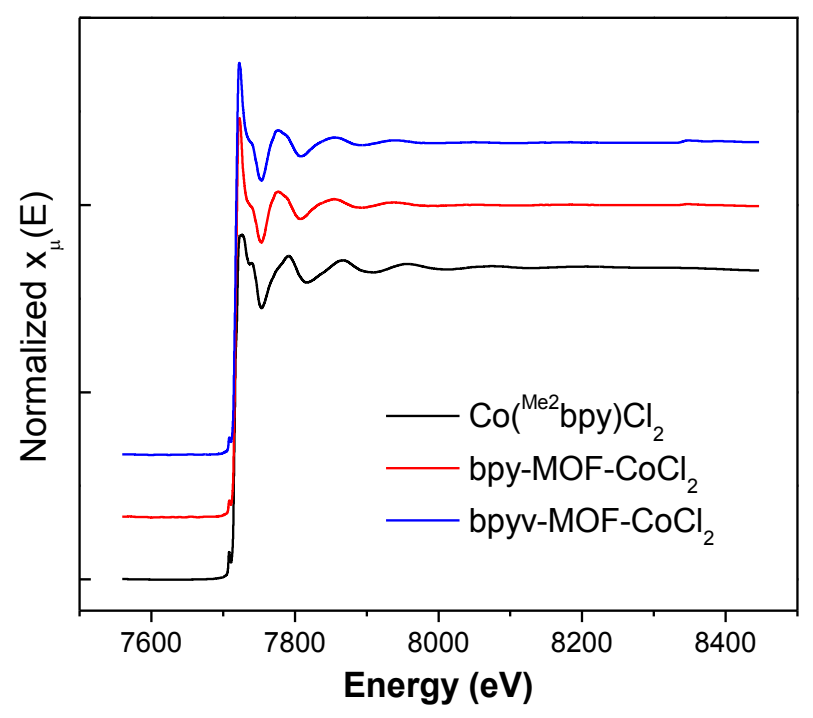

Figure S25. Normalized $\mu$ (E) XAS spectra for $\mathrm{Co}\left({ }^{\mathrm{Me} 2} \mathrm{bpy}\right) \mathrm{Cl}_{2}$ (black), bpy-MOF-CoCl (red), and bpyv-MOF- $\mathrm{CoCl}_{2}$ (blue).

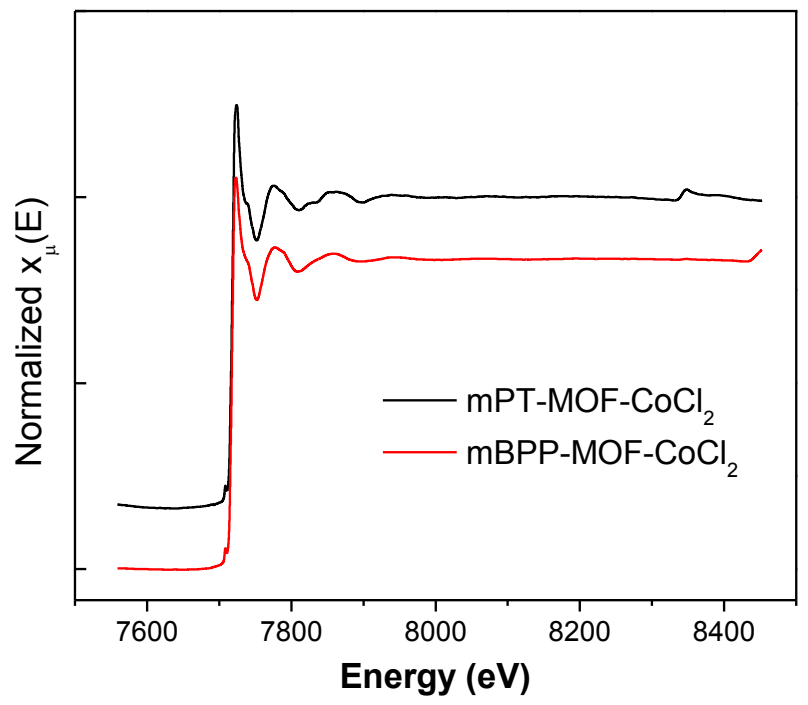

Figure S26. Normalized $\mu(\mathrm{E}) \mathrm{XAS}$ spectra for $\mathrm{mPT}-\mathrm{MOF}-\mathrm{CoCl}_{2}$ (black) and mBPP$\mathrm{MOF}-\mathrm{CoCl}_{2}$ (red). 


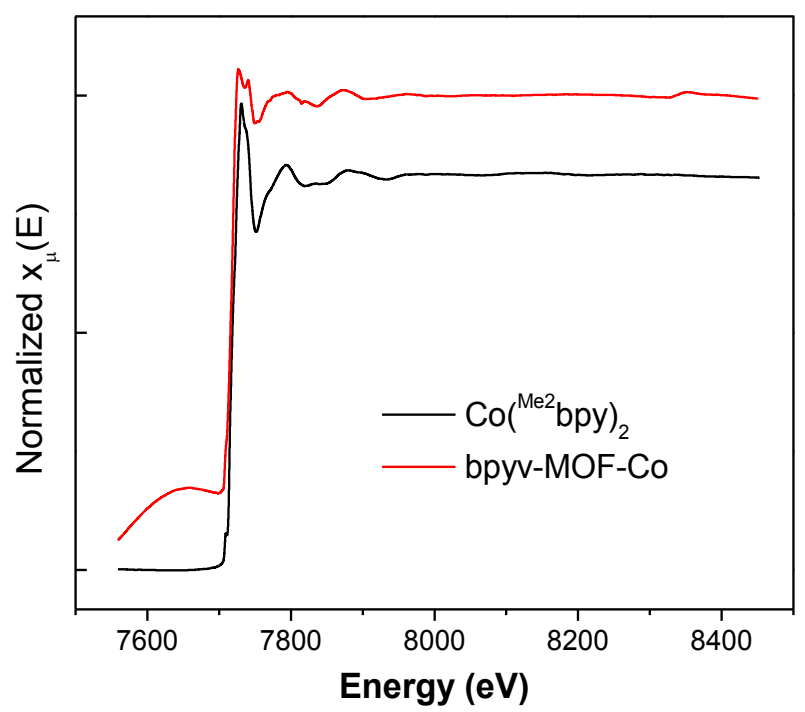

Figure S27. Normalized $\mu(\mathrm{E})$ XAS spectra for $\mathrm{Co}\left({ }^{\mathrm{Me} 2} \mathrm{bpy}\right)_{2}$ (black) and bpyv-MOF-Co (red).

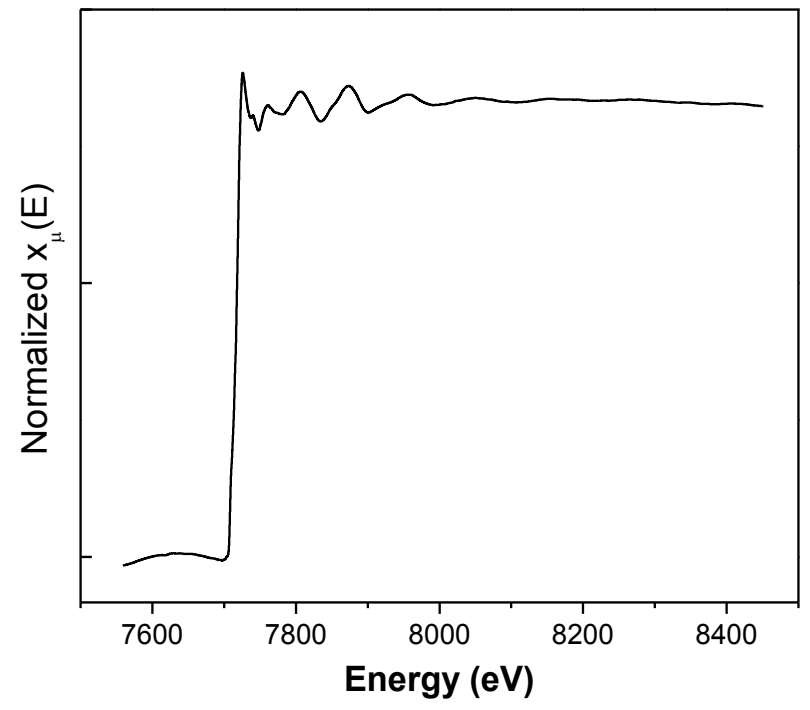

Figure S28. Normalized $\mu(E)$ XAS spectra for Co nanoparticles. 


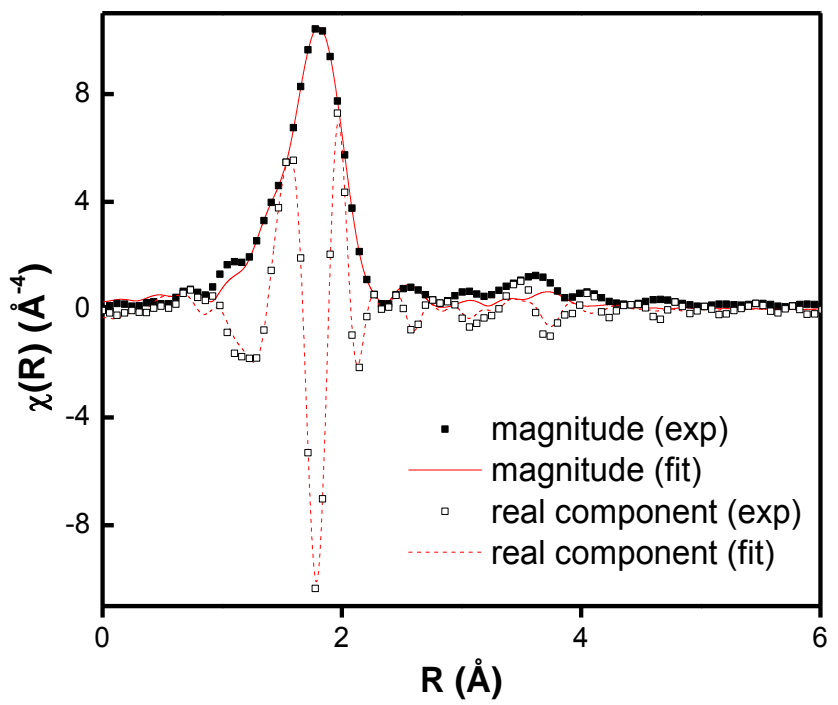

Figure S29. Experimental EXAFS spectra and fits of $\mathrm{Co}\left({ }^{\mathrm{Me} 2} \mathrm{bpy}\right) \mathrm{Cl}_{2}$ in $\mathrm{R}$ space showing the magnitude (solid squares, solid line) and real component (hollow squares, dash line).

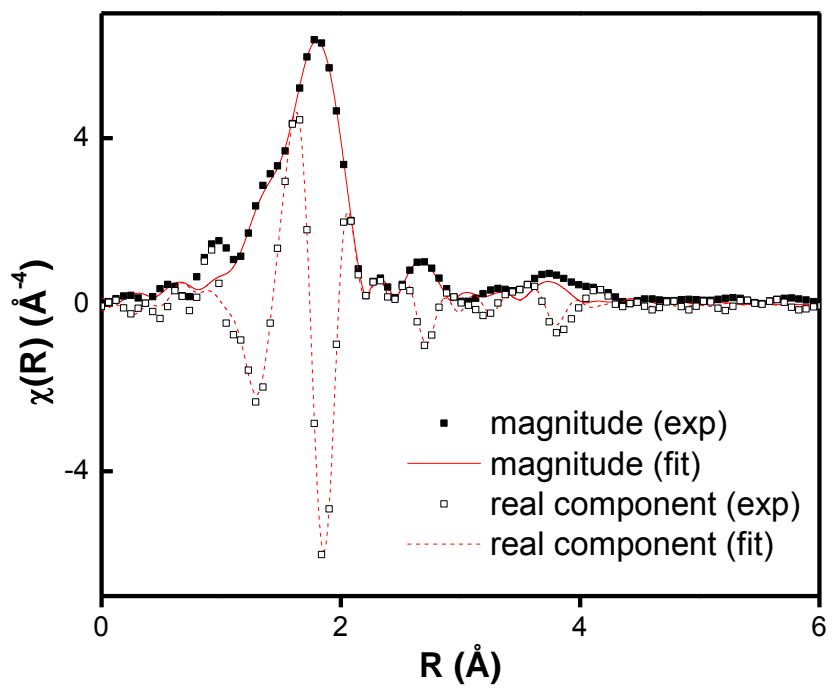

Figure S30. Experimental EXAFS spectra and fits of bpy-MOF-CoCl 2 in $\mathrm{R}$ space showing the magnitude (solid squares, solid line) and real component (hollow squares, dash line). 


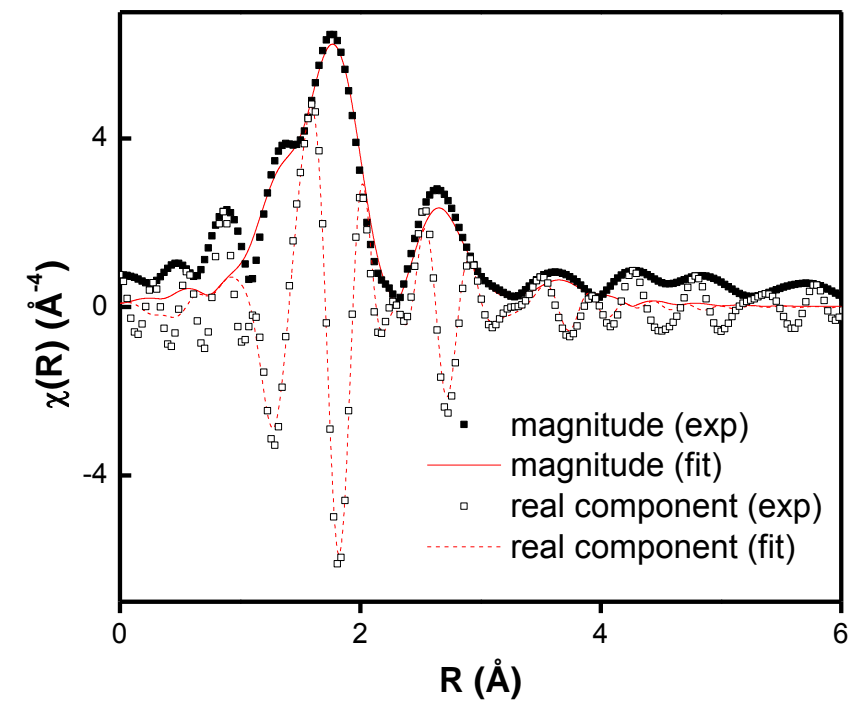

Figure S31. Experimental EXAFS spectra and fits of mPT-MOF-CoCl $l_{2}$ in $\mathrm{R}$ space showing the magnitude (solid squares, solid line) and real component (hollow squares, dash line).

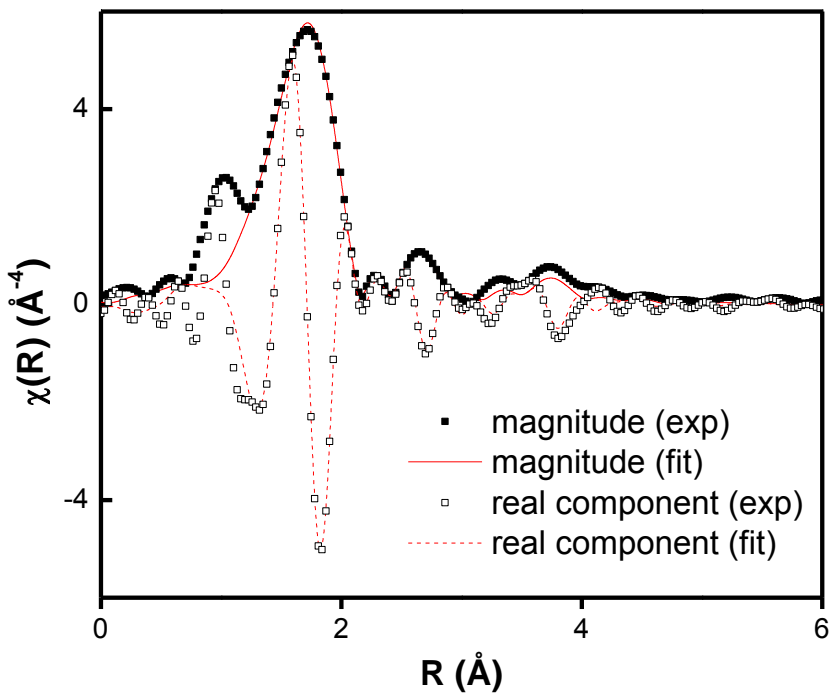

Figure S32. Experimental EXAFS spectra and fits of mBPP-MOF-CoCl 2 in $\mathrm{R}$ space showing the magnitude (solid squares, solid line) and real component (hollow squares, dash line). 


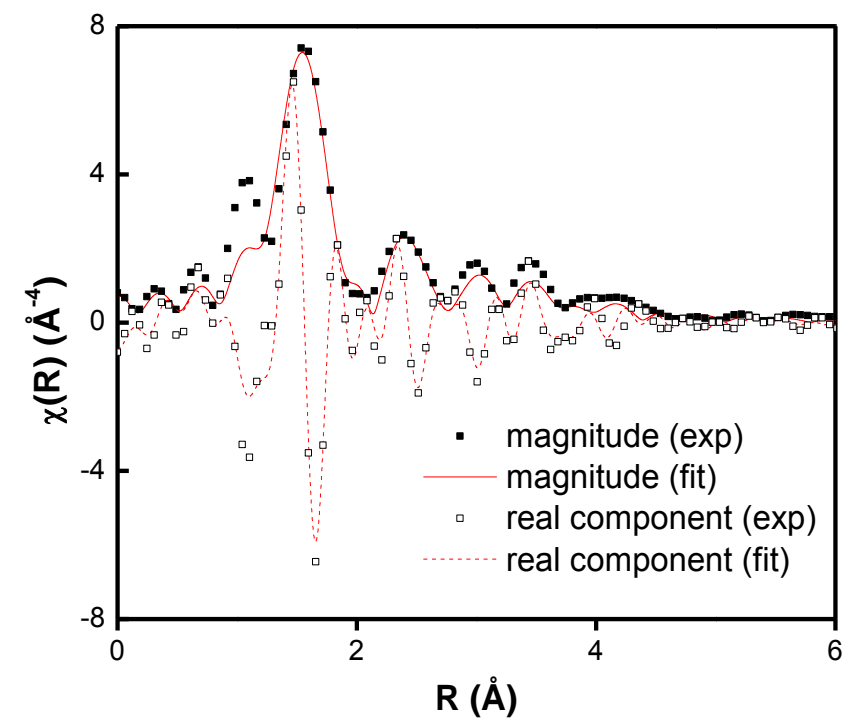

Figure S33. Experimental EXAFS spectra and fits of $\mathrm{Co}\left({ }^{\mathrm{Me}} 2 \mathrm{bpy}\right)_{2}$ in R space showing the magnitude (solid squares, solid line) and real component (hollow squares, dash line).

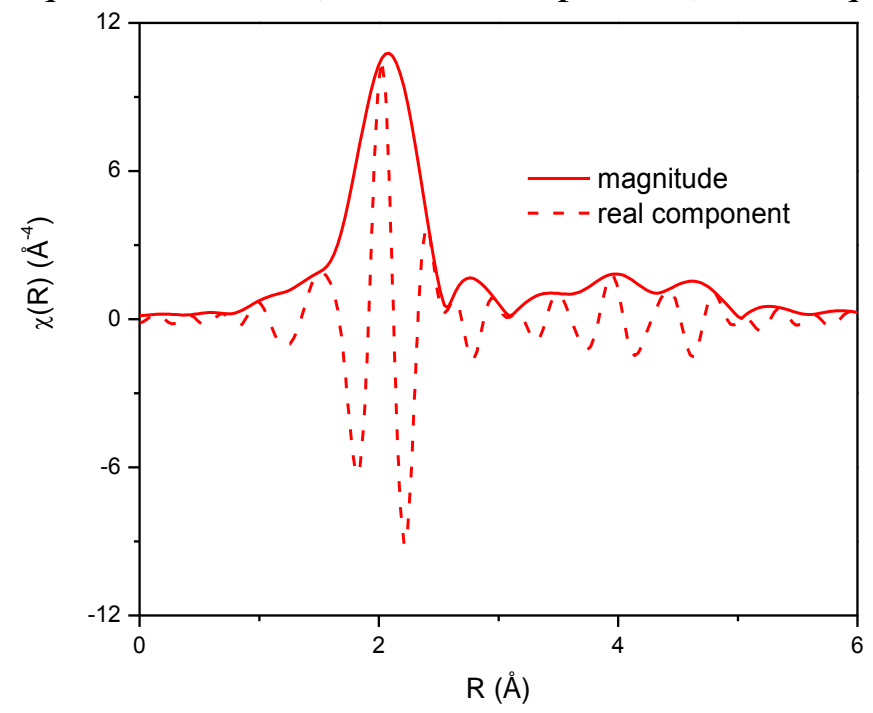

Figure S34. Experimental EXAFS spectra of Co nanoparticles (generated from $\mathrm{CoCl}_{2}$ and 5 equiv. of $\mathrm{NaBEt}_{3} \mathrm{H}$ in THF at rt) in $\mathrm{R}$ space showing the magnitude (solid line) and real component (dash line).

\section{DFT calculations}

All quantum chemical calculations were performed using the density functional theory (DFT) functional B3LYP/6-311G+g(d,p) as implemented in the Gaussian 09 software suite. ${ }^{10}$ Electronic structure complexes were optimized at the unrestricted level. 

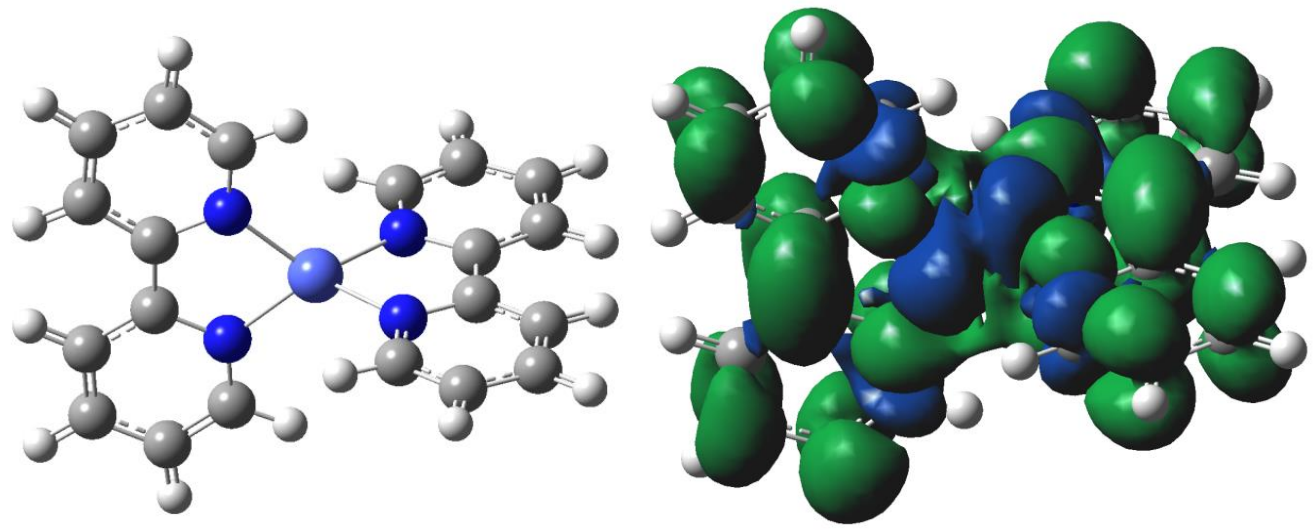

Figure S35. Optimized structure and calculated spin density of $\operatorname{Co}(b p y)_{2}$.

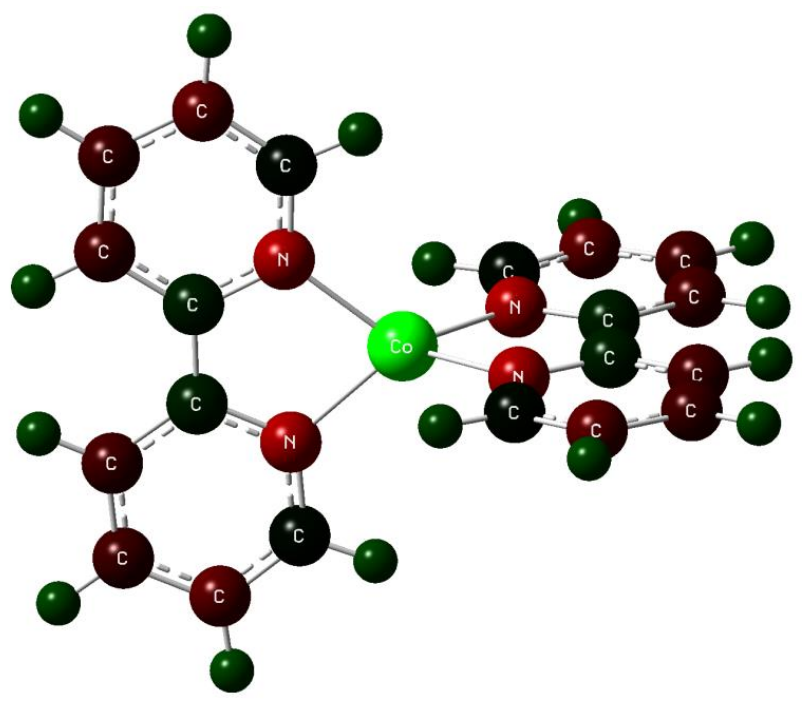

Figure S36. Atomic charge distribution of $\mathrm{Co}(\mathrm{bpy})_{2}$ as calculated by NBO population analysis, atoms bearing positive and negative charges are denoted by green and red colors, respectively.
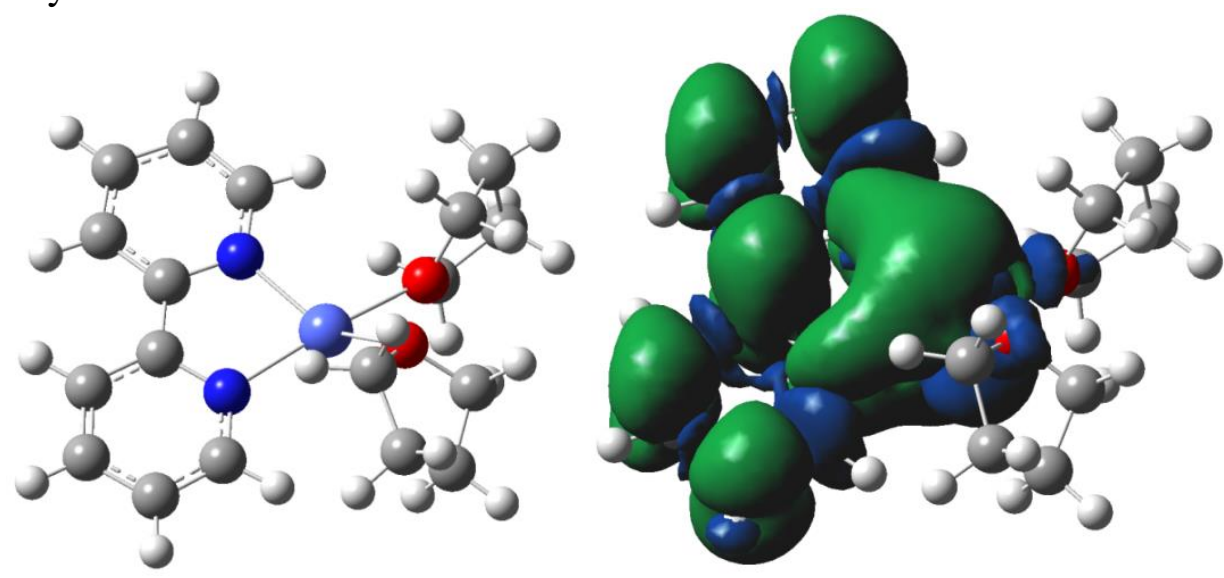

Figure S37. Optimized structure and calculated spin density of $\mathrm{Co}(\mathrm{bpy})(\mathrm{THF})_{2}$. 
Table S6. NBO charge population analysis of Co(bpy $)_{2}$.

\begin{tabular}{|l|l|}
\hline Fragment & NBO charge population \\
\hline Co & 0.902 \\
\hline bpy & -0.451 \\
\hline
\end{tabular}

Table S7. NBO charge population analysis of Co(bpy)(THF) $)_{2}$.

\begin{tabular}{|l|l|}
\hline Fragment & NBO charge population \\
\hline Co & 0.594 \\
\hline bpy & -0.784 \\
\hline THF(1) & 0.098 \\
\hline THF(2) & 0.091 \\
\hline
\end{tabular}

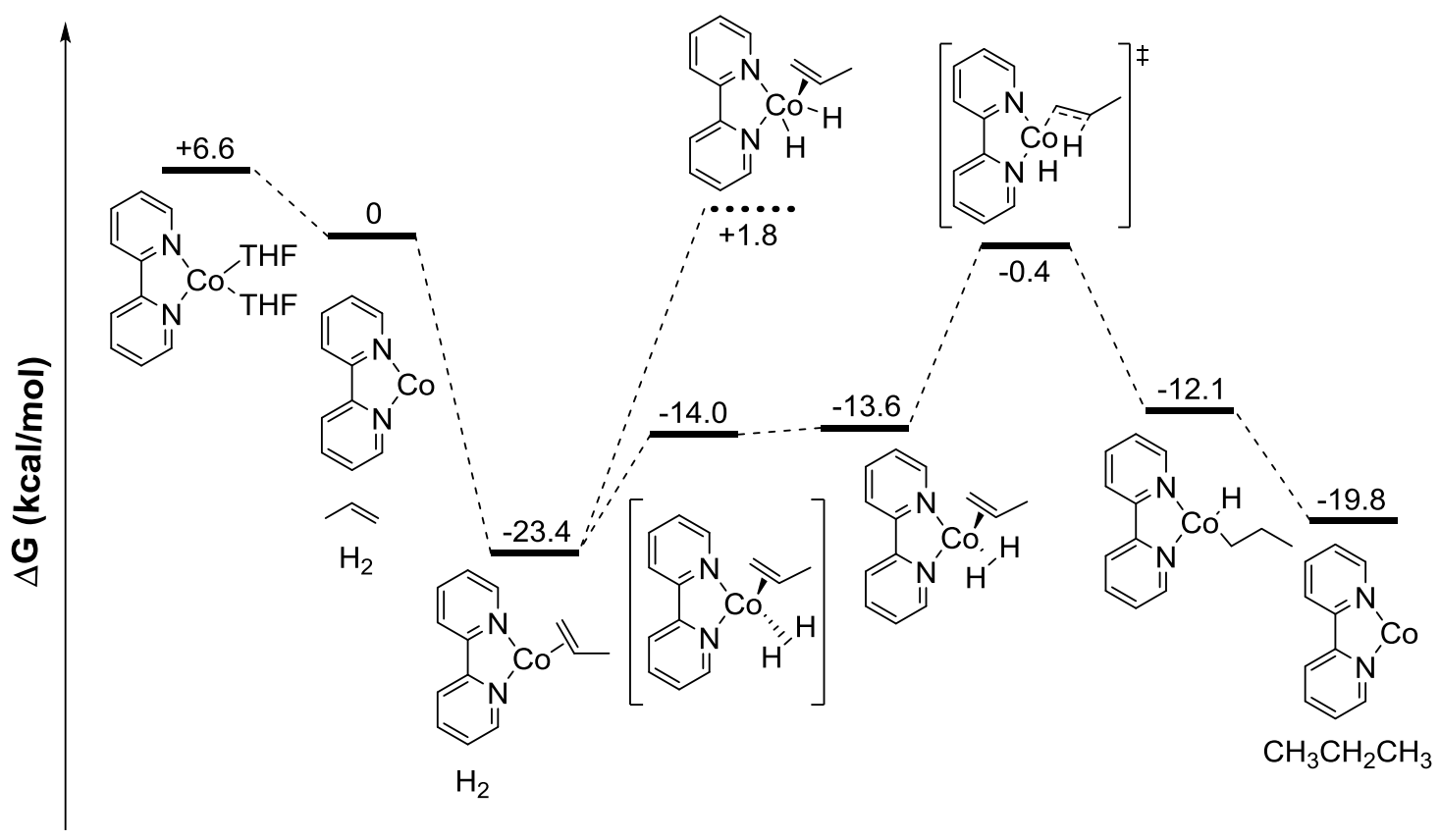

Figure S38. Calculated energy diagram of the proposed catalytic cycle. Transition state calculations suggest that the $\mathrm{H}_{2}$ binding step does not have a well-defined transition state with the potential energy surface landscape near the $\sigma$-complex minimum rather flat. The $\sigma-\mathrm{H}_{2}$ complex rather than dihydride is proposed to be a key intermediate as suggested by the calculated energy difference. A $\Delta G^{\ddagger}$ of $13.2 \mathrm{kcal} / \mathrm{mol}$ was calculated for the $\sigma-C A M$ step, suggesting metathesis be the rate-determining step. 


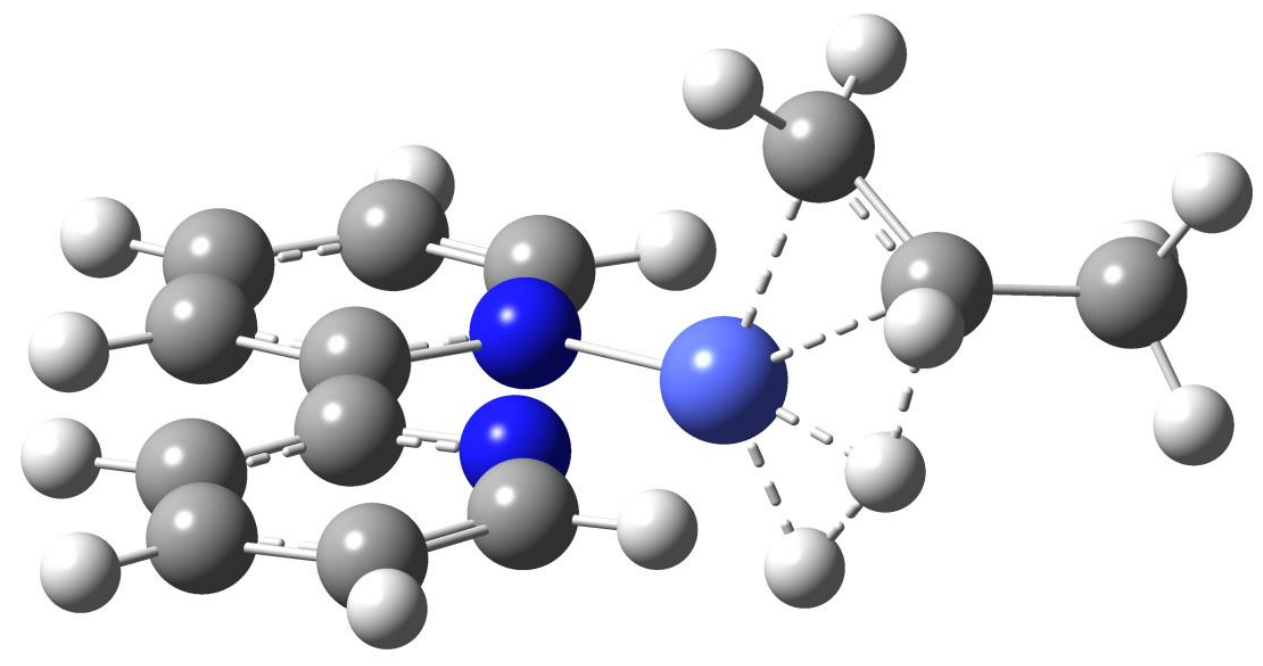

Figure S39. The optimized structure of $\sigma-\mathrm{CAM}$ transition state.

\section{Procedures for Catalytic Hydrogenation of Olefins}

7.1. General procedure for MOF-Co catalyzed hydrogenation of olefins. In a nitrogen-filled glove box, $\mathrm{MOF}-\mathrm{CoCl}_{2}(2.0 \mathrm{mg}, 0.1 \mathrm{~mol} \% \mathrm{Co})$ in $1.0 \mathrm{~mL} \mathrm{THF}$ was charged into a glass vial. $\mathrm{NaBEt}_{3} \mathrm{H}(15 \mu \mathrm{L}, 1.0 \mathrm{M}$ in THF) was then added to the vial and the mixture was stirred for 1 hour. The solid was then centrifuged, washed with THF twice, and transferred to a glass vial in $0.5 \mathrm{~mL}$ THF. The olefin substrate $(2.0 \mathrm{mmol})$ was added to the vial. Then the vial was placed in a Parr reactor which was sealed under nitrogen atmosphere and charged with hydrogen to 40 bar. After stirring at room temperature for $18 \mathrm{~h}$, the pressure was released and the MOF catalyst was removed from the reaction mixture via centrifugation. Mesitylene (internal standard) was added to the organic extracts and the yield of the product was determined by integrations of the product and mesitylene peaks in the ${ }^{1} \mathrm{H}$ NMR spectra in $\mathrm{CDCl}_{3}$.

\subsection{Reuse and recycle experiment procedure for bpyv-MOF-Co-catalyzed hydrogenation of 1-octene.}



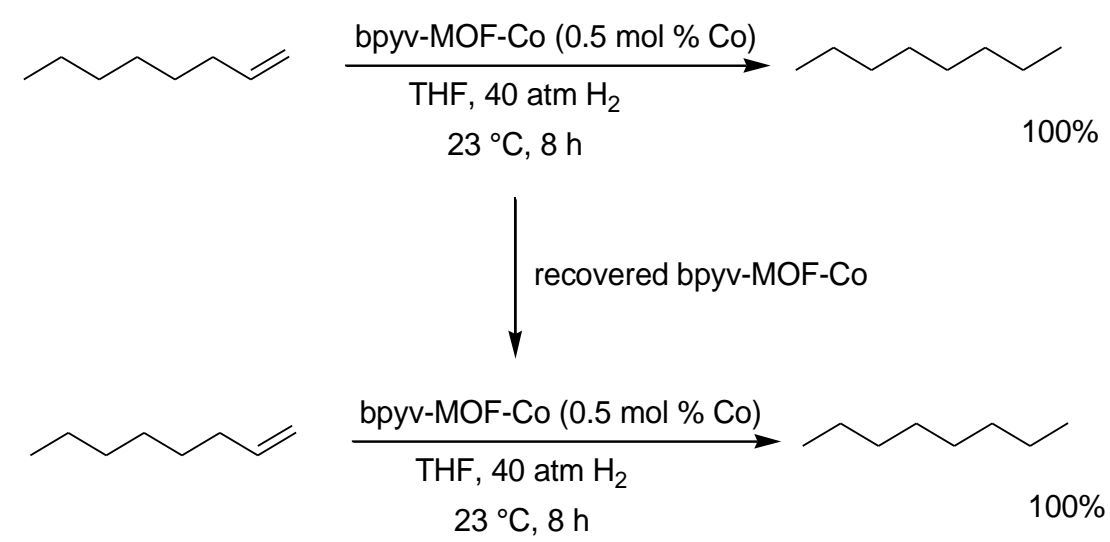

Figure S40. Recycle and reuse of bpyv-MOF-Co for hydrogenation of 1-octene to $n$ octane.

In a nitrogen-filled glove box, bpyv-MOF-CoCl $2(5.0 \mathrm{mg}, 0.5 \mathrm{~mol} \% \mathrm{Co})$ in 1.0 $\mathrm{mL}$ THF was charged into a glass vial with a Teflon-liner cap. $\mathrm{NaBEt}_{3} \mathrm{H}(30 \mu \mathrm{L}, 1.0 \mathrm{M}$ in THF) was then added to the vial and the mixture was shaken for an hour on a rotation mixer. The solid was then centrifuged, washed with THF twice, and transferred to a glass vial in $0.5 \mathrm{~mL}$ THF. 1-octene $(160 \mu \mathrm{L}, 1.0 \mathrm{mmol})$ was then added to the vial. The vial was then placed in a Parr reactor. The reactor was sealed under nitrogen atmosphere and charged with hydrogen to 40 bar. The pressure was released after $8 \mathrm{~h}$, and the MOF catalyst was centrifuged out from suspension and extracted with THF 2-3 times in glove box. The organic extracts were combined and conversions were calculated based on integration of substrate and product peaks in the crude ${ }^{1} \mathrm{H}$ NMR spectra.

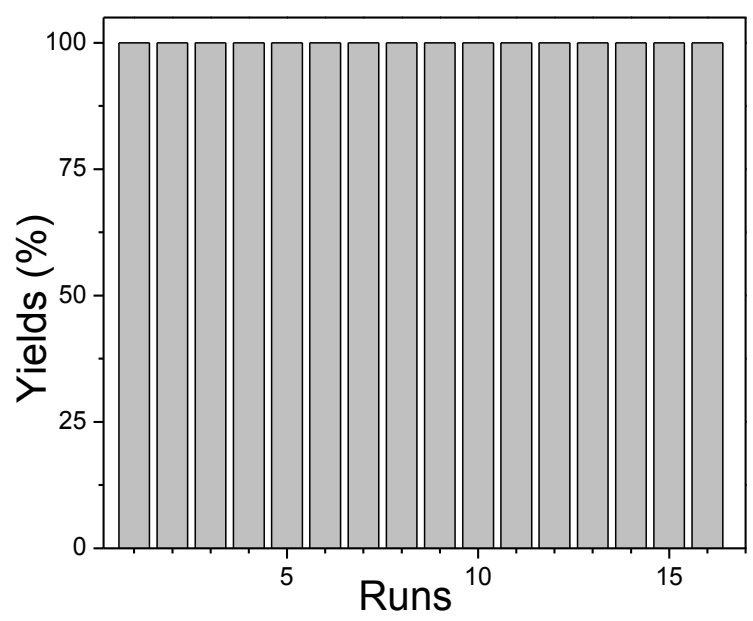

Figure S41. Plot of yields (\%) of $n$-octane at different runs in the reuse experiments of bpy-MOF-Co for hydrogenation of 1-octene. The Co loadings were $0.5 \mathrm{~mol} \%$. 


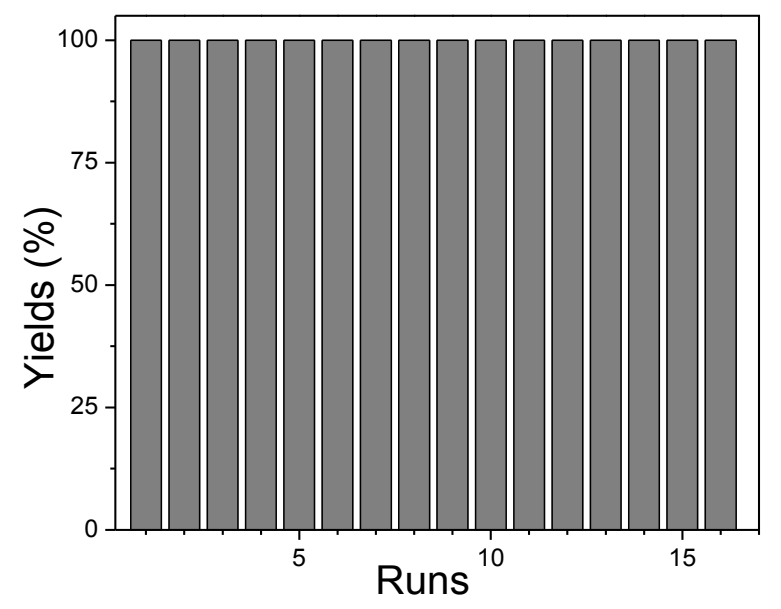

Figure S42. Plots of yields (\%) of $n$-octane at different runs in the reuse experiments of bpyv-MOF-Co for hydrogenation of 1 -octene. The Co loadings were $0.5 \mathrm{~mol} \%$.

\subsection{Test of "heterogeneity" of the MOF catalysis}

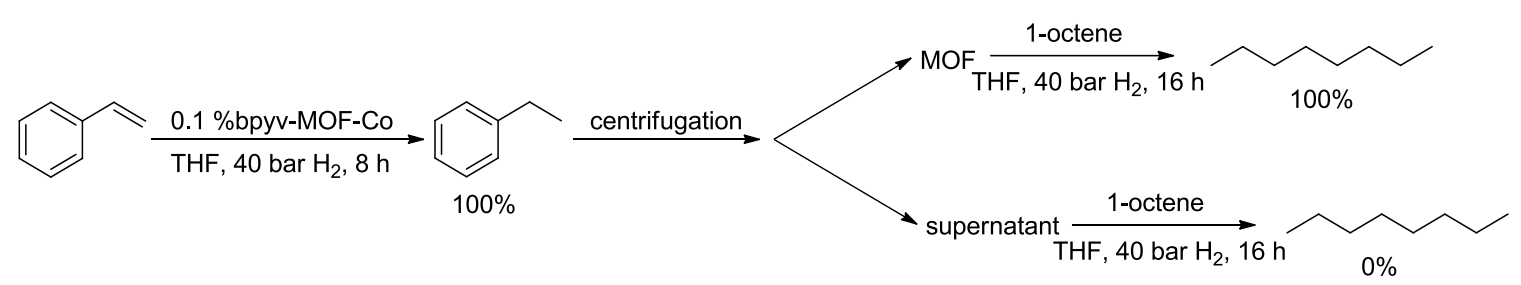

Figure S43. The hydrogenation of 1-octene stopped after removing bpyv-MOF-Co from the reaction mixture, demonstrating the "heterogeneous" nature of MOF catalysis.

In a nitrogen-filled glove box, bpyv-MOF-CoCl $2(2.0 \mathrm{mg}, 0.1 \mathrm{~mol} \% \mathrm{Co})$ in 1.0 $\mathrm{mL}$ THF was charged into a glass vial. $\mathrm{NaBEt}_{3} \mathrm{H}(15 \mu \mathrm{L}, 1.0 \mathrm{M}$ in THF) was then added to the vial and the mixture was stirred for 1 hour. The solid was then centrifuged, washed with THF twice, and transferred to a glass vial containing $0.5 \mathrm{~mL}$ THF. Styrene $(230 \mu \mathrm{L}$, $2.0 \mathrm{mmol}$ ) was then added to the vial. The vial was then placed in a Parr reactor which was sealed under nitrogen atmosphere and later charged with hydrogen to 40 bar. After 8 $\mathrm{h}$, the pressure was released and the MOF catalyst was centrifuged out from suspension. Conversion of styrene to ethylbenzene (100\%) was determined based on integration of substrate and product peaks in the crude ${ }^{1} \mathrm{H}$ NMR spectra. Ethylbenzene was afforded quantitatively as determined by ${ }^{1} \mathrm{H}$ NMR spectroscopy.

After the solid and supernatant were separated, 1-octene $(320 \mu \mathrm{L}, 2.0 \mathrm{mmol})$ was added to each of the portions which were later placed in a Parr reactor, sealed under 
nitrogen and charged with hydrogen to 40 bar. After $16 \mathrm{~h}$, the pressure was released and the supernatant was separated from the solid catalyst when necessary. Conversions of 1octene to $n$-octane determined based on integration of substrate and product peaks in the crude ${ }^{1} \mathrm{H}$ NMR spectra were $100 \%$ in presence of MOF and $0 \%$ in presence of supernatant. This test thus proved that the MOF is the exact catalyst for olefin hydrogenation.

\subsection{Comparison of catalytic activities of MOF-Co catalysts in alkene hydrogenation with their homogeneous controls.}

To demonstrate the unique role of MOFs in stabilizing the catalytically active species, the catalytic activities of the MOF-Co catalysts were compared with a molecular control, $\mathrm{Co}\left({ }^{\mathrm{Me} 2} \mathrm{bpy}\right) \mathrm{Cl}_{2}$ ( ${ }^{\mathrm{Me} 2}$ bpy $=6,6^{\prime}$-dimethyl-2,2'-bipyridine $) .{ }^{6}$ Upon treatment with $\mathrm{NaEt}_{3} \mathrm{BH}, 0.1 \mathrm{~mol} \% \mathrm{Co}\left({ }^{\mathrm{Me} 2} \mathrm{bpy}\right) \mathrm{Cl}_{2}$ or $\mathrm{CoCl}_{2}$ hydrogenated styrene to ethylbenzene in $100 \%$ conversion, however, no conversion was obtained with 0.01 mol \% catalyst loading under identical reaction conditions (entries 1-4, Table S8). In contrast, at a 0.01 mol \% Co loading, both bpy-MOF-CoCl 2 and bpyv-MOF- $\mathrm{CoCl}_{2}$ afforded ethylbenzene quantitatively. Catalytic activity of the molecular control decreased dramatically in presence of mercury, indicating the contribution of catalytic activity from Conanoparticles formed during hydrogenation reactions. In contrast, the activities of MOFsCo catalysts were not affected by the presence of mercury. The significantly enhanced stability and activity of MOF-Co catalysts compared to their homogeneous controls are likely due to active site isolation within MOF cavities which prevent any intermolecular deactivation pathways.

Table S8. Olefin hydrogenation catalyzed by MOF catalysts and homogeneous controls. ${ }^{a}$

Entry \begin{tabular}{ccc}
$\frac{\text { precatalyst }+\mathrm{NaBEt}_{3} \mathrm{H}}{40 \text { bar } \mathrm{H}_{2}, \mathrm{THF}}$ \\
Precatalyst & Conversion $(\%)^{b}$ \\
\hline
\end{tabular}




\begin{tabular}{ccc}
\hline 1 & $0.1 \% \mathrm{CoCl}_{2}$ & $100(78)$ \\
2 & $0.1 \% \mathrm{Me}^{\mathrm{bpy}-\mathrm{CoCl}_{2}}$ & $100(28)$ \\
3 & $0.01 \% \mathrm{CoCl}_{2}$ & 0 \\
4 & $0.01 \% \mathrm{Me}^{\mathrm{bpy}} \mathrm{CoCl}_{2}$ & 0 \\
5 & $0.01 \%$ bpy-MOF-Co & 100 \\
6 & $0.01 \%$ bpyv-MOF-Co & 100 \\
7 & $0.1 \%$ mBPP-MOF & 0 \\
8 & $0.01 \%$ mPT-MOF-Co & 100 \\
9 & $0.01 \%$ mBPP-MOF-Co & 100 \\
\hline
\end{tabular}

${ }^{a}$ Reaction conditions: $0.1 \%$ or $0.01 \%$ of precatalyst with 5 equiv. of $\mathrm{NaBEt}_{3} \mathrm{H}, 40 \mathrm{bar}_{2}$, THF, room temperature, $20 \mathrm{~h} .{ }^{b}$ Conversions in parentheses are obtained in presence of metallic mercury.

\subsection{Comparison of catalytic activities of MOF-Co catalysts in alkene hydrogenation.}

Table S9. Olefin hydrogenation catalyzed by MOF catalysts under identical reaction conditions. ${ }^{a}$

\begin{tabular}{|c|c|c|c|c|}
\hline Entry & Substrate & Co-catalyst & Time & Yield $(\%)^{b}$ \\
\hline $\begin{array}{l}1 \\
2 \\
3 \\
4\end{array}$ & & $\begin{array}{c}0.01 \% \text { bpy-MOF-Co } \\
0.01 \% \text { bpyv-MOF-Co } \\
0.01 \% \text { mPT-MOF-Co } \\
0.01 \% \text { mBPP-MOF-Co }\end{array}$ & $\begin{array}{l}30 \mathrm{~h} \\
30 \mathrm{~h} \\
30 \mathrm{~h} \\
30 \mathrm{~h}\end{array}$ & $\begin{array}{c}16 \\
21 \\
36 \\
100\end{array}$ \\
\hline $\begin{array}{l}5 \\
6 \\
7 \\
8\end{array}$ & & $\begin{array}{l}0.1 \% \text { bpy-MOF-Co } \\
0.1 \% \text { bpyv-MOF-Co } \\
0.1 \% \text { mPT-MOF-Co } \\
0.1 \% \text { mBPP-MOF-Co }\end{array}$ & $\begin{array}{l}24 \mathrm{~h} \\
24 \mathrm{~h} \\
24 \mathrm{~h} \\
24 \mathrm{~h}\end{array}$ & $\begin{array}{c}11 \\
53 \\
81 \\
100\end{array}$ \\
\hline $\begin{array}{c}9 \\
10 \\
11 \\
12\end{array}$ & & $\begin{array}{c}0.1 \% \text { bpy-MOF-Co } \\
0.1 \% \text { bpyv-MOF-Co } \\
0.1 \% \text { mPT-MOF-Co } \\
0.1 \% \text { mBPP-MOF-Co }\end{array}$ & $\begin{array}{l}96 \mathrm{~h} \\
96 \mathrm{~h} \\
96 \mathrm{~h} \\
96 \mathrm{~h}\end{array}$ & $\begin{array}{l}16 \\
26 \\
59 \\
95\end{array}$ \\
\hline
\end{tabular}

${ }^{a}$ Reaction conditions: $\mathrm{MOF}-\mathrm{CoCl}_{2}(1.0 \mu \mathrm{mol} \mathrm{Co}), 8$ equiv of $\mathrm{NaBEt}_{3} \mathrm{H}(1.0 \mathrm{M}$ in THF) w.r.t. Co, alkene, THF (1.0 mL), 40 bar $\mathrm{H}_{2}, 23{ }^{\circ} \mathrm{C} .{ }^{b}$ Yields were determined by ${ }^{1} \mathrm{H}$ NMR with mesitylene as the internal standard.

Table S9 shows the order of catalytic activity of MOF-catalysts in hydrogenation is mBPP-MOF-Co > mPT-MOF-Co > bpyv-MOF-Co > bpy-MOF-Co. 
Table S10. Hydrogenation of alkenes catalyzed by mBPP-MOF-Co under identical mild reaction conditions to earlier reports. ${ }^{a}$

\begin{tabular}{|c|c|c|c|}
\hline Entry & Substrate & $\begin{array}{c}\text { Yield (Time) with } 5 \text { mol \% } \\
\text { mBPP-MOF-Co }\end{array}$ & $\begin{array}{l}\text { Yield (Time) with } 5 \text { mol\% } \\
\qquad\left({ }^{\mathrm{iPr}} \mathrm{CNC}\right) \mathrm{CoCH}_{3}{ }^{11}\end{array}$ \\
\hline 1 & & $96 \%(1 \mathrm{~h})$ & $>95 \%(5 \mathrm{~h})$ \\
\hline 2 & & Run 1: 100\% (3 h) & \\
\hline 3 & 2 & Run 2: $96 \%$ (2 h) & $>95 \%(5 \mathrm{~h})$ \\
\hline 4 & & Run 3: $100 \%(2.5 \mathrm{~h})$ & \\
\hline 5 & & $100 \%(12 \mathrm{~h})$ & $95 \%(120 h)$ \\
\hline
\end{tabular}

${ }^{b}$ Reaction conditions: 4 atm of $\mathrm{H}_{2}$ at $22^{\circ} \mathrm{C}$.

\subsection{Determination of the rate law for mBPP-MOF-Co-catalyzed hydrogenation of styrene in THF.}

The rate law of the hydrogenation of styrene was determined by the method of initial rates (up to $10 \%$ conversion). The reactions were conducted in THF (total volume of solution was $1.0 \mathrm{~mL}$ ) at $23{ }^{\circ} \mathrm{C}$ in a small vial within a Parr reactor (inside volume of Parr reactor: $320 \mathrm{~mL}$ ). To determine the rate dependence on one reagent, the concentration or pressure (in case of $\mathrm{H}_{2}$ ) of that reagent was varied, while the concentration or pressure of other reagents and the total volume of the solution $(1.0 \mathrm{~mL})$ were held constant. After hydrogenation for $120 \mathrm{sec}$, the concentration of the product ethylbenzene was determined by GC using mesitylene as the internal standard. The rates refer to the rates of product (ethylbenzene) in units of $\mathrm{M} \cdot \mathrm{s}^{-1}$. To determine the rate dependence on styrene, the concentration of styrene was varied between $1.11-5.57 \mathrm{M}$, while the concentration of $\mathrm{Co}$ was $6.43 \times 10^{-5} \mathrm{M}$ and pressure of $\mathrm{H}_{2}$ was 40 bar (Figure S43). To determine the rate dependence on catalyst, the concentration of Co was varied between $1.28 \times 10^{-5}-7.71 \times 10^{-5} \mathrm{M}$, while the concentration of styrene was $3.34 \mathrm{M}$ and pressure of $\mathrm{H}_{2}$ was 40 bar (Figure $3 \mathrm{f}$ ). To determine the rate dependence on $\mathrm{H}_{2}$, the 
pressure of $\mathrm{H}_{2}$ was varied between 20 - 50 bar, while the concentration of styrene and Co $3.34 \mathrm{M}$ and $2.57 \times 10^{-5} \mathrm{M}$, respectively (Figure $3 \mathrm{f}$ ).

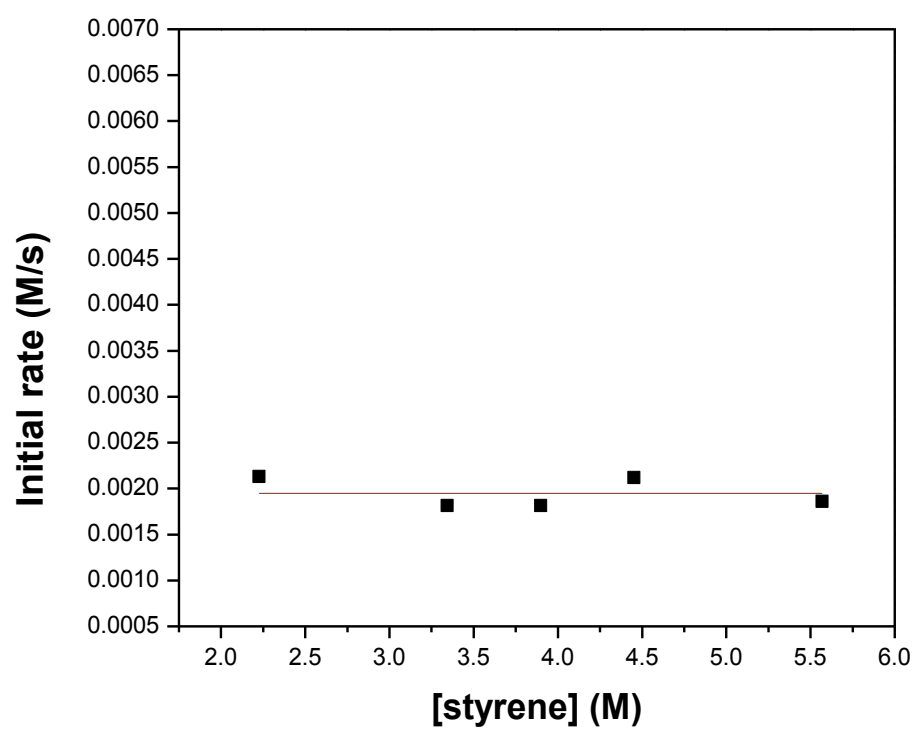

Figure S44. Plot of initial rate (d[ethylbenzene]/dt) versus [styrene $]_{\text {initial }}$ for first $120 \mathrm{sec}$ $(<10 \%$ conversion) showing the independence of initial rates on the alkene concentrations. $[\mathrm{Co}]=6.43 \times 10^{-5} \mathrm{M} ; p_{\mathrm{H} 2}=40$ bar.

\subsection{Investigation of substrate size effect on hydrogenation catalytic activity.}

a)

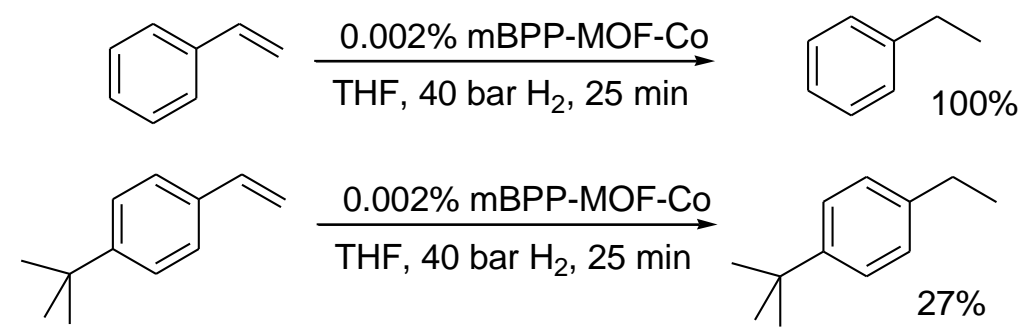

Figure S45. The hydrogenation of styrene and 4-tert-butylstyrene catalyzed by mBPPMOF-Co under identical reaction conditions.

In a nitrogen-filled glove box, mBPP-MOF-CoCl $2(0.5 \mathrm{mg})$ in $1.0 \mathrm{~mL}$ THF was charged into a glass vial. $\mathrm{NaBEt}_{3} \mathrm{H}(15 \mu \mathrm{L}, 1.0 \mathrm{M}$ in THF) was then added to the vial and the mixture was stirred for 1 hour. The solid was then centrifuged, washed with THF twice, and then divided into two glass vials containing $0.5 \mathrm{~mL}$ THF. Styrene $(0.32 \mathrm{~mL}$, $2.78 \mathrm{mmol})$ dissolved in $1.18 \mathrm{~mL}$ THF was added to one vial. 4-tert-butylstyrene (0.51 
$\mathrm{mL}, 2.78 \mathrm{mmol}$ ) dissolved in $0.99 \mathrm{~mL}$ was charged into another vial. The two vials were then placed in a Parr reactor which was sealed under nitrogen atmosphere and later charged with hydrogen to 40 bar. After $25 \mathrm{~min}$, the pressure was released and $10.0 \mu \mathrm{L}$ mesitylene was added to each vial as an internal standard. The yields of ethylbenzene and 1-tert-butyl-4-ethylbenzene were determined based on integration of substrate and product peaks in the crude ${ }^{1} \mathrm{H}$ NMR spectra. Ethylbenzene and 1-tert-butyl-4ethylbenzene were afforded in $100 \%$ and $27 \%$ yields, respectively. This experiment demonstrates that catalysis is facilitated by Co-sites both inside the pores and on the outside of the MOFs, not the framework surface alone.

b)<smiles>[CH2+]c1ccc(CC)cc1</smiles>

Figure S46. The hydrogenation of styrene and 4-tert-butylstyrene catalyzed by bpyMOF-Co under identical reaction conditions.

In a nitrogen-filled glove box, bpy-MOF-CoCl $2(0.75 \mathrm{mg})$ in $1.0 \mathrm{~mL}$ THF was charged into a glass vial. $\mathrm{NaBEt}_{3} \mathrm{H}(15 \mu \mathrm{L}, 1.0 \mathrm{M}$ in THF) was then added to the vial and the mixture was stirred for 1 hour. The solid was then centrifuged, washed with THF twice, and then charged into a glass vial containing $1.0 \mathrm{~mL}$ THF. Styrene $(0.32 \mathrm{~mL}, 2.78$ $\mathrm{mmol})$ and 4-tert-butylstyrene $(0.51 \mathrm{~mL}, 2.78 \mathrm{mmol})$ were added to the mixture. The vial was then placed in a Parr reactor which was sealed under nitrogen atmosphere and later charged with hydrogen to 40 bar. After $24 \mathrm{~h}$, the pressure was released and $10.0 \mu \mathrm{L}$ mesitylene was added to each vial as an internal standard. The yields of ethylbenzene and 1-tert-butyl-4-ethylbenzene were determined based on integration of substrate and product peaks in the crude ${ }^{1} \mathrm{H}$ NMR spectra. Ethylbenzene and 1-tert-butyl-4ethylbenzene were afforded in $100 \%$ and $27 \%$ yields, respectively. This experiment also demonstrates that catalysis is facilitated by Co-sites both inside the pores and on the outside of the MOFs, not the framework surface alone. 


\section{A typical procedure for catalytic hydroboration of alkenes}

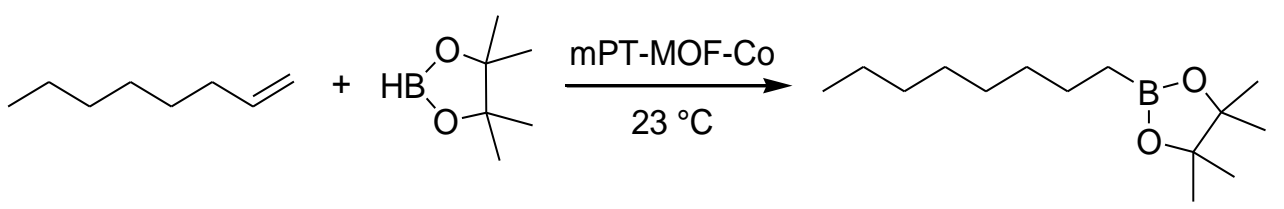

In a glovebox, $\mathrm{mPT}-\mathrm{MOF}-\mathrm{CoCl}_{2}(1.0 \mathrm{mg}, 0.01 \mathrm{~mol} \% \mathrm{Co})$ was charged into a small vial and $0.5 \mathrm{~mL}$ THF was added. Then, $6 \mu \mathrm{L} \mathrm{NaBEt}{ }_{3} \mathrm{H}(1.0 \mathrm{M}$ in THF) was added to the vial and the mixture was stirred slowly for $1 \mathrm{~h}$ in the glovebox. The solid was centrifuged out of suspension and washed with THF two times. Pinacolborane $(0.37 \mathrm{~mL}, 2.4 \mathrm{mmol})$ was added to the solid in the vial and then 1-octene $(0.31 \mathrm{~mL}, 2.0 \mathrm{mmol})$ was added. The resultant mixture was slowly stirred at room temperature for 3 days in the glovebox until complete conversion of 1-octene as monitored by GC. The solid was centrifuged out of suspension and extracted with hexane for 2-3 times. The combined organic extracts were concentrated in vacuo to yield the pure product $(0.470 \mathrm{~g}, 1.96 \mathrm{mmol}, 98 \%)$.

\section{A typical procedure for $\mathrm{mPT}-\mathrm{MOF}-\mathrm{Co}$ catalyzed $\mathrm{C}-\mathrm{H}$ borylation of neat arenes}

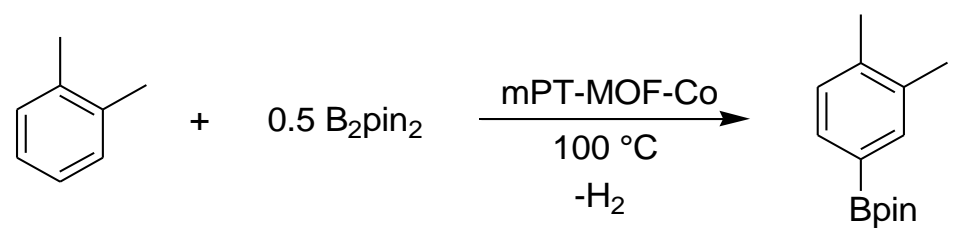

In a glovebox, mPT-MOF-CoCl $2(3.0 \mathrm{mg}, 0.1 \mathrm{~mol} \% \mathrm{Co})$ was charged into a small vial and $0.5 \mathrm{~mL}$ THF was added. Then, $20 \mu \mathrm{L} \mathrm{NaBEt}_{3} \mathrm{H}$ (1.0 M in THF) was added to the vial and the mixture was stirred slowly for $1 \mathrm{~h}$ in the glovebox. The solid was centrifuged out of suspension and washed with THF for two times and with $o$-xylene for one time. $\mathrm{B}_{2} \mathrm{pin}_{2}(54.8 \mathrm{mg}, 0.216 \mathrm{mmol})$ in $4.0 \mathrm{~mL} o$-xylene was added to the vial and the resultant mixture was transferred to a Schlenk tube. The tube was heated to reflux under nitrogen at $100{ }^{\circ} \mathrm{C}$ for $9 \mathrm{~d}$. The reaction mixture was cooled to room temperature and the solid was centrifuged out of suspension. The extract was passed through a short plug of celite and then concentrated in vacuo to give pure 1,2-dimethyl-4-(4,4,5,5-tetramethyl1,3,2-dioxaborolan-2-yl)benzene as (90 mg, $0.389 \mathrm{mmol}, 90 \%$ ). 
Time evaluation studies for $\mathrm{C}-\mathrm{H}$ borylation of arenes using mPT-MOF-Co and PTCo as catalysts under identical reaction conditions. $\mathrm{B}_{2} \mathrm{pin}_{2}(38.1 \mathrm{mg}, 0.15 \mathrm{mmol})$, mPT-MOF-Co (3.0 mg, $0.1 \mathrm{~mol} \% \mathrm{Co}$ ) in $4 \mathrm{~mL} m$-xylene were charged into a Schlenk tube in a glovebox. Another Schlenk tube was charged with $\mathrm{B}_{2} \mathrm{pin}_{2}(41 \mathrm{mg}, 0.161 \mathrm{mmol})$, PT-Co (1.0 mg, $3.2 \mu \mathrm{mol}, 1.0 \mathrm{~mol} \% \mathrm{Co})$ in $4 \mathrm{~mL} m$-xylene. The two storage tubes were heated at $100{ }^{\circ} \mathrm{C}$ simultaneously and the conversion (\%) of the product was monitored by $\mathrm{GC}$ using mesitylene as an internal standard in $1 \mathrm{~d}$ interval of heating.

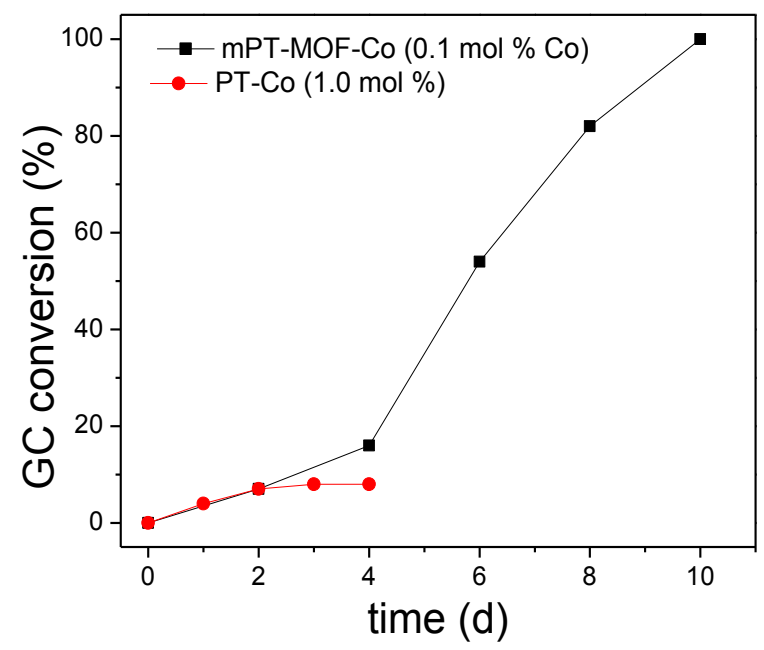

Figure S47. Plots of GC conversion (\%) vs time (h) for $\mathrm{C}-\mathrm{H}$ borylation of $m$-xylene using mPT-MOF-Co $(0.1 \mathrm{~mol} \%)$ and PT-Co $(1.0 \mathrm{~mol} \%)$ as catalysts at $100{ }^{\circ} \mathrm{C}$ under $\mathrm{N}_{2}$.

\section{Procedures for catalytic hydroboration of carbonyl compounds}

In a glovebox, bpyv-MOF-CoCl $2(1.0 \mathrm{mg}, 0.05 \mathrm{~mol} \% \mathrm{Co})$ was charged into a small vial and $0.5 \mathrm{~mL}$ THF was added. Then, $8 \mu \mathrm{L} \mathrm{NaBEt}_{3} \mathrm{H}(1.0 \mathrm{M}$ in THF) was added to the vial and the mixture was stirred slowly for $1 \mathrm{~h}$ in the glovebox. The solid was centrifuged out of suspension and washed with hexane two times. Then, the solid in $5 \mathrm{~mL}$ hexane was transferred to a vial, and aldehyde or ketone $(1.56 \mathrm{mmol})$ and pinacolborane $(1.70 \mathrm{mmol})$ was added in the vial. The resultant mixture was stirred at room temperature for 1-2 days in the glovebox and the progress of the reaction was monitored by GC. After complete conversion, the solid was centrifuged out of suspension and extracted with hexane for 2-3 times. The combined organic extracts were concentrated in vacuo to yield the pure product. 
A typical procedure for bpyv-MOF-Co catalyzed hydroboration of ketones. In a glovebox, bpyv-MOF-CoCl $2(1.0 \mathrm{mg}, 0.005 \mathrm{~mol} \% \mathrm{Co})$ was charged into a small vial and $0.5 \mathrm{~mL}$ THF was added. Then, $8 \mu \mathrm{L} \mathrm{NaBEt}_{3} \mathrm{H}$ (1.0 M in THF) was added to the vial and the mixture was stirred slowly for $1 \mathrm{~h}$ in the glovebox. The solid was centrifuged out of suspension and washed with hexane two times. Then, the solid in $10 \mathrm{~mL}$ hexane was transferred to a vial, and 4-methoxyacetophenone $(2.35 \mathrm{~g}, 15.6 \mathrm{mmol})$ and pinacolborane (2.68 $\mathrm{mL}, 17.2 \mathrm{mmol}$ ) was added in the vial. The resultant mixture was stirred at room temperature for 1-2 days in the glovebox and the progress of the reaction was monitored by GC. After complete conversion, the solid was centrifuged out of suspension and extracted with hexane for 2-3 times. The combined organic extracts were concentrated in vacuo to yield the pure borate ester product as a colorless oil (4.33 g, $15.6 \mathrm{mmol}, 100 \%)$.

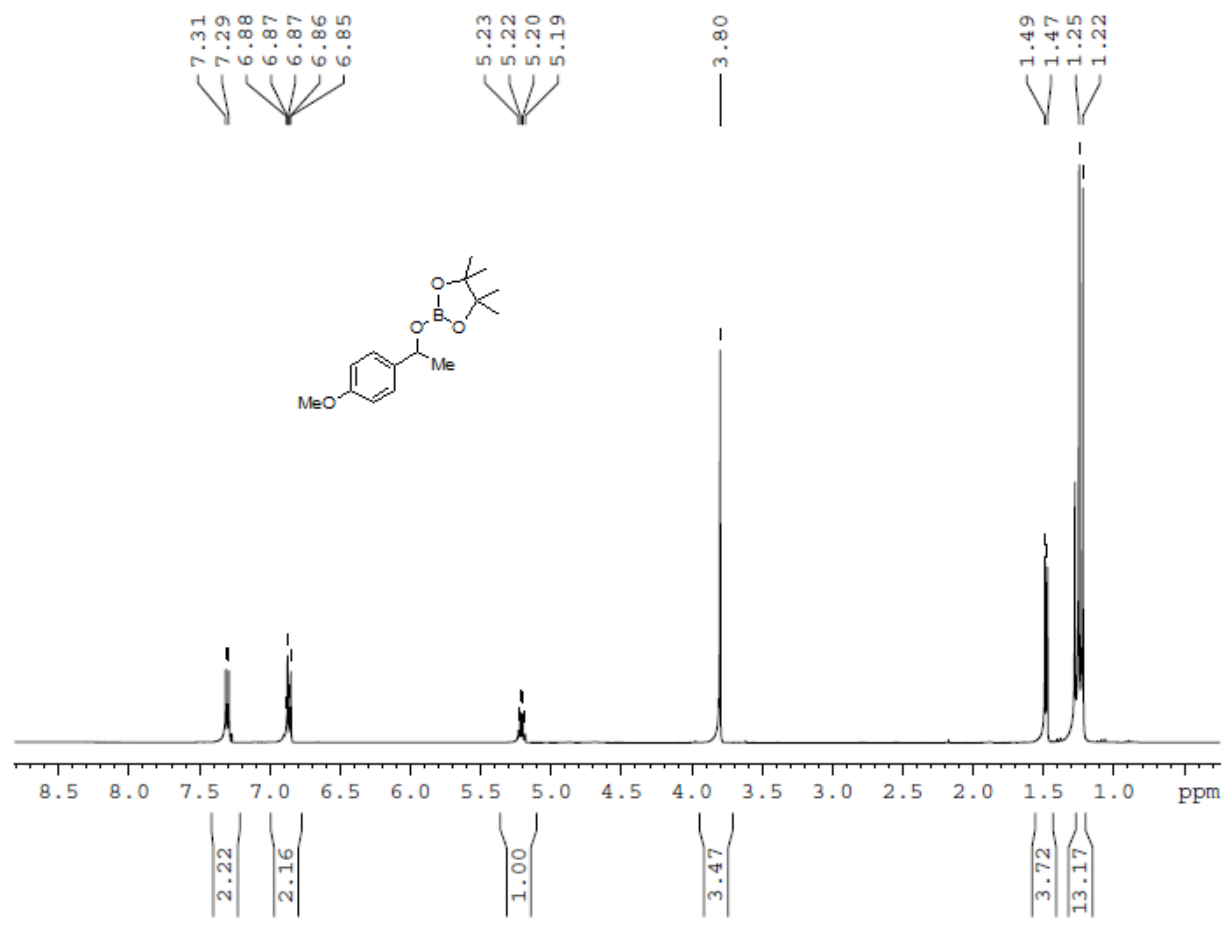

Figure S48. ${ }^{1} \mathrm{H}$ NMR spectrum ( $400 \mathrm{MHz}, \mathrm{CDCl}_{3}$ ) of crude borate ester product obtained from hydroboration of 4-methoxtacetophenone.

\section{References}

(1) Manna, K.; Zhang, T.; Greene, F. X.; Lin, W. J. Am. Chem. Soc. 2015, 137, 2665-2673.

(2) Manna, K.; Zhang, T.; Lin, W. J. Am. Chem. Soc. 2014, 136, 6566-6569.

(3) Wang, C.; deKrafft, K. E.; Lin, W. J. Am. Chem. Soc. 2012, 134, 7211-7214. 
(4) Li, L.; Tang, S.; Wang, C.; Lv, X.; Jiang, M.; Wu, H.; Zhao, X. Chem Commun 2014, 50, 2304-2307.

(5) Sheldrick, G. Acta Crystallographica Section A 2008, 64, 112-122.

(6) Akbarzadeh Torbati, N.; Rezvani, A. R.; Safari, N.; Saravani, H.; Amani, V. Acta Crystallographica Section E 2010, 66, m1284.

(7) Ravel, B.; Newville, M. Journal of Synchrotron Radiation 2005, 12, 537-541.

(8) Rehr, J. J.; Albers, R. C. Reviews of Modern Physics 2000, 72, 621-654.

(9) Stieber, S. C. E.; Milsmann, C.; Hoyt, J. M.; Turner, Z. R.; Finkelstein, K. D.; Wieghardt, K.; DeBeer, S.; Chirik, P. J. Inorganic Chemistry 2012, 51, 3770-3785.

(10) M. J. Frisch, G. W. Trucks, H. B. Schlegel, G. E. Scuseria, M. A. Robb, J. R. Cheeseman, G. Scalmani, V. Barone, B. Mennucci, G. A. Petersson, H. Nakatsuji, M. Caricato, X. Li, H. P. Hratchian, A. F. Izmaylov, J. Bloino, G. Zheng, J. L. Sonnenberg, M. Hada, M. Ehara, K. Toyota, R. Fukuda, J. Hasegawa, M. Ishida, T. Nakajima, Y. Honda, O. Kitao, H. Nakai, T. Vreven, J. A. Montgomery, Jr., J. E. Peralta, F. Ogliaro, M. Bearpark, J. J. Heyd, E. Brothers, K. N. Kudin, V. N. Staroverov, T. Keith, R. Kobayashi, J. Normand, K. Raghavachari, A. Rendell, J. C. Burant, S. S. Iyengar, J. Tomasi, M. Cossi, N. Rega, J. M. Millam, M. Klene, J. E. Knox, J. B. Cross, V. Bakken, C. Adamo, J. Jaramillo, R. Gomperts, R. E. Stratmann, O. Yazyev, A. J. Austin, R. Cammi, C. Pomelli, J. W. Ochterski, R. L. Martin, K. Morokuma, V. G. Zakrzewski, G. A. Voth, P. Salvador, J. J. Dannenberg, S. Dapprich, A. D. Daniels, O. Farkas, J. B. Foresman, J. V. Ortiz, J. Cioslowski, and D. J. Fox, Gaussian 09, Revision C.01; Gaussian, Inc.: Wallingford, CT, 2010.

(11) Yu, R. P.; Darmon, J. M.; Milsmann, C.; Margulieux, G. W.; Stieber, S. C. E.; DeBeer, S.; Chirik, P. J. J. Am. Chem. Soc. 2013, 135, 13168-13184. 